\title{
Métodos de documentación, análisis y conservación de trazados arquitectónicos a tamaño natural
}

\section{Documentation, analysis and conservation of full-size architectural tracings}

\author{
José Calvo López, \\ Universidad Politécnica de Cartagena \\ jose.calvo@upct.es \\ Miguel Taín Guzmán \\ Universidade de Santiago de Compostela \\ miguel.tain@usc.es
}

\author{
Miguel Ángel Alonso Rodríguez \\ Universidad Politécnica de Madrid \\ miguel.alonso@upm.es \\ Idoia Camiruaga Osés \\ Consorcio de Santiago \\ idoia@consorciodesantiago.es
}

\begin{abstract}
RESUMEN
Los trazados a tamaño natural o monteas han desempeñado un papel importante a lo largo de la historia de la arquitectura, pues no plantean los problemas de cambios de escala asociados a los dibujos en papel y por tanto permiten controlar la ejecución de forma muy precisa. Como consecuencia, aportan datos de gran interés para el conocimiento de la historia constructiva de los edificios donde se han conservado, a condición de contar con una documentación rigurosa y confrontarla con levantamientos igualmente precisos de los edificios o elementos constructivos que representan. El artículo recoge los métodos empleados por los autores para documentar estos trazados y compararlos con obras construidas, en una serie de experiencias ejemplos españoles de la Edad Moderna, y finaliza con algunas consideraciones acerca de los retos que plantea la conservación de estas fuentes materiales esenciales para la historia de la arquitectura y de la construcción.
\end{abstract}

Palabras clave: Trazados a tamaño natural; monteas; cantería; estereotomía; levantamiento; topografía; estación total; fotogrametría; escáner láser.

\begin{abstract}
Full-size tracings have played an important role in architectural history; they do not pose the scale change problems involved with drawings in paper, allowing a precise execution of any architectural member. As a result, they furnish valuable data about the constructive history of these members, provided that a precise survey, both of the tracing and the architectural member, is available in order to compare both and measure the precision of the execution. This paper explains the methods used by the authors in the documentation of a number of tracings in Early Modern Spanish buildings, including also the survey of the architectural members they depict, ending with the challenges posed by the conservation of these key material sources of architectural and construction history.
\end{abstract}

Keywords: Full-size tracings; stonecutting; stereotomy; surveying; topography; total station; photogrammetry; laser scanning.

Recibido: 01-07-2015. Aceptado: 02-09-2015.

Cómo citar este artículo / Citation

Calvo López, J., Taín Guzmán, M., Alonso Rodríguez, M. Á. y Camiruaga Osés, I. 2015: "Métodos de documentación, análisis y conservación de trazados arquitectónicos a tamaño natural", Arqueología de la Arquitectura, 12: e026. doi: http://dx.doi.org/10.3989/arq.arqt.2015.024

\section{Copyright}

(c) 2015 CSIC. Este es un artículo de acceso abierto distribuido bajo los términos de la licencia Creative Commons Attribution-Non Commercial (by-nc) Spain 3.0. 


\section{LOS TRAZADOS A TAMAÑO NATURAL EN LA HISTORIA DE LA ARQUITECTURA}

Los medios de representación han desempeñado un papel relevante a lo largo de la historia de la arquitectura, pues sólo en el caso de construcciones relativamente sencillas, en un contexto de reglas fijas bien conocidas, es posible construir sin una definición gráfica del elemento que se pretende levantar (Cabezas 2011; López 2011: 184-190; Rabasa 2000). Ahora bien, esta prefiguración de los edificios o elementos constructivos se puede llevar a cabo a escala reducida, sobre papiro, pergamino o papel; o bien a escala natural, sobre suelos o muros. Los dibujos a escala reducida presentan la ventaja de la facilidad de transporte y del menor esfuerzo de trazado, pero también el inconveniente del alto precio del papiro, el pergamino y, en las primeras fases desde su aparición, del papel. Por el contrario, los trazados a tamaño natural o a escalas grandes tienen a su favor la gratuidad del soporte y, sobre todo, la precisión como dibujos de ejecución, al no depender de los errores cometidos al cambiar de escala.

Los dibujos a escala reducida se han mostrado, al menos desde la época de Vasari, como fuentes imprescindibles de la historiografía de la arquitectura; han permitido analizar las intenciones de los arquitectos, los cambios de proyecto, o incluso las disputas entre varios artífices participantes en el mismo edificio. No ha ocurrido lo mismo con los trazados a escala natural o a escalas grandes, conocidos como épures en francés o monteas en castellano. En primer lugar, muchos de ellos han desaparecido, en ocasiones ocultos bajo la propia obra, y en otros casos por el simple paso del tiempo o la incuria, mientras que los dibujos a escalas reducidas se conservaban en archivos o bibliotecas. Pero además, los dibujos a escala natural, ligados por lo general pero no siempre a la ejecución directa de la obra, han sido víctimas de un prejuicio elitista e idealista que limita la arquitectura al momento de la concepción y desprecia a los meros ejecutores, entendiendo esta fase como la reproducción mecánica de la idea inicial. En ocasiones se presenta esta posición como 'albertiana', pero probablemente no hace más que trasladar anacrónicamente a épocas pasadas los modos de producción de nuestro tiempo, con una organización industrial de los procesos de proyecto y ejecución y un control férreo del segundo por el primero; veremos que en realidad esta concepción sólo se materializa a partir de la Revolución Industrial.
Todo esto ha hecho olvidar el papel desempeñado por los trazados a tamaño natural, al menos desde la Antigüedad hasta la Ilustración (v. Ruiz de la Rosa 1987). Es bien conocido el pasaje vitruviano que habla de las tres especies de la disposición, pero no es frecuente señalar que la ichnographia alude en su nombre a la huella, y que Vitruvio menciona expresamente al solis arearum. Lothar Haselberger $(1983,1994)$ ha estudiado ejemplos helenísticos y romanos de trazados a tamaño natural, como los del templo de Apolo en Dydima y el frontón del pronaos del Panteón, situado en el Mausoleo de Augusto. Dos rasgos destacan en estos ejemplos clásicos: no aparecen proyecciones en sentido estricto, pues los trazados representan elementos en el mismo plano; y en el caso de un dibujo para el cálculo del éntasis en una columna en Dydima, se practica un cambio de escala, pero únicamente en uno de los ejes; la sección de la columna se traza como un arco de circunferencia, que se convertirá en una elipse al deshacer el cambio de escala, obteniendo así el éntasis de la columna. Todo esto señala que no estamos tratando con representaciones que pretendan llevar la imagen del elemento a construir a un observador externo, sino con estudios introspectivos preparados por los constructores del templo para uso propio.

Apenas se han encontrado trazados de este tipo datados en la Alta Edad Media, pero algunas leyendas sugieren que las prácticas antiguas pervivieron, al menos en el imaginario colectivo. Según la tradición, el papa Liborio marcó el plano de Santa María la Mayor con una azada sobre la nieve milagrosamente caída en pleno verano romano. Cuando San Pedro, San Pablo y San Esteban despiertan al abad Gunzo para fundar la primera abadía de Cluny, le entregan larguísimas cuerdas. Entre los trazados medievales más antiguos se encuentran los de las abadías de Jervaulx y Bylands, representando basas de columna, en algunos casos a escalas grandes, pero no a tamaño natural (Fergusson 1979). En el período gótico aparecen ya numerosos trazados de basas, gabletes, rosas o pináculos, como los de Soissons, Saint-Quentin, Chartres, ClermontFerrand, Narbona, York, Wells o Sevilla (Barnes 1972; Bucher 1977; Branner 1987; Branner 1960; Claval 1990; Bessac 1985; Harvey 1968; Holton 2006; Ruiz de la Rosa 1996). Es de destacar que son frecuentes las rosas incisas en piedra a escalas grandes, como las de Saint-Quentin, pero no a tamaño natural; por el contrario, los gabletes y tracerías se representan casi siempre en verdadera magnitud. Esto indica que los constructores góticos disponían de métodos eficaces para cambiar de escala figuras 
radiales, pero que no confiaban en la aplicación de estos procedimientos a otro tipo de formas.

Es llamativa la ausencia de trazados de bóvedas nervadas; tan solo han aparecido algunas monteas dieciochescas de bóvedas de crucería simple y de terceletes en Galicia (Taín 2003a, 2003b, 2003c; Taín, Alonso, Calvo y Natividad 2012) (fig. 1). Esta ausencia en el gótico medieval parece deberse a dos razones diferentes. Como ha señalado Enrique Rabasa (2000: 96-121), es posible resolver las jarjas y las claves de una bóveda de crucería simple sin dibujos o trazados, empleando plantillas en las jarjas y marcas simples en la superficie superior de la clave u operating surface (Willis 1842; Pérez de los Ríos y Rabasa 2014). Al mismo tiempo, en las bóvedas rectangulares o cuadradas la simetría de la pieza garantiza que los dos arcos ojivos o diagonales se cruzan en la clave principal. Ahora bien, con la aparición de la bóveda de terceletes el problema se complica, pues ya no podemos asegurar que los extremos de los terceletes y la ligadura se encuentren en el espacio en un punto resuelto con una clave secundaria. Esto exige una regla para el trazado de los terceletes en planta, para asegurar la simetría del conjunto. Entre las primeras bóvedas de terceletes están las conocidas crazy vaults de Lincoln (Frankl 1953), que no respetan este principio, y de hecho se pueden apreciar notables diferencias de trazado entre una bóveda y otra; además, el experimento apenas tuvo continuidad (v. por ejemplo López, Senent, Alonso, Calvo y Natividad 2015). Pero además es necesario asegurar que los extremos de terceletes y ligaduras están a la misma altura, lo que exige la construcción de un alzado o elevación de los nervios. Los dos problemas se abordan en un esquema sin texto del cuaderno de Hernán Ruiz (1998: 46v) que permite incluso medir la inclinación de los planos de lecho y sobrelecho de los nervios en su encuentro con las claves secundarias y principal (Rabasa 1996, 2000: 121-130) (fig. 2); lo esencial del procedimiento, con importantes variantes y adiciones, aparece también en los manuscritos de Alonso de Vandelvira (1977), Alonso de Guardia (c. 1600) y Josep Gelabert (2011), así como en los tratados franceses de Philibert de L'Orme (1567), Mathurin Jousse (1642) y François Derand (1643), entre otros muchos.

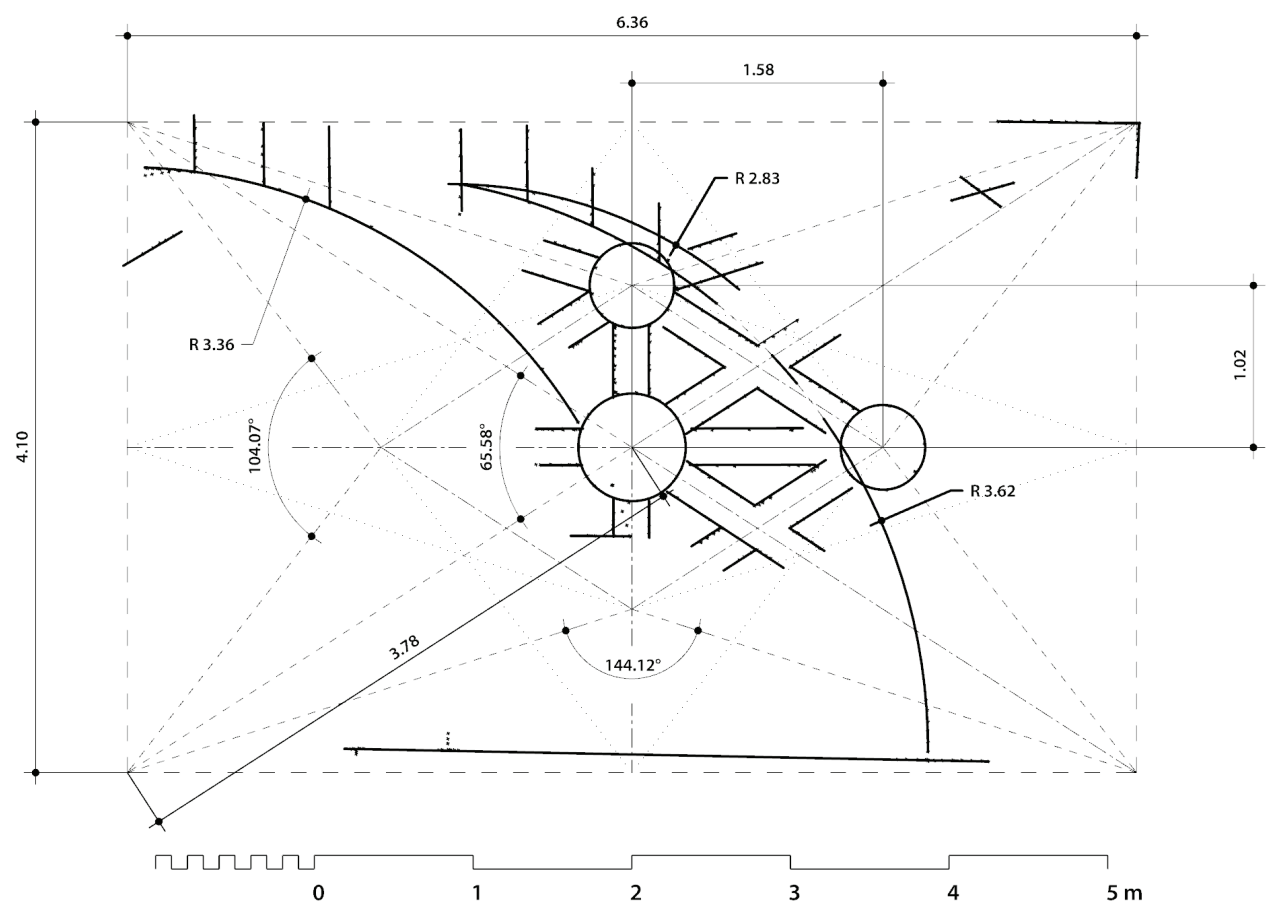

Figura 1. Trazado de bóveda de cantería en la capilla de Santa Catalina de la catedral de Tui. 


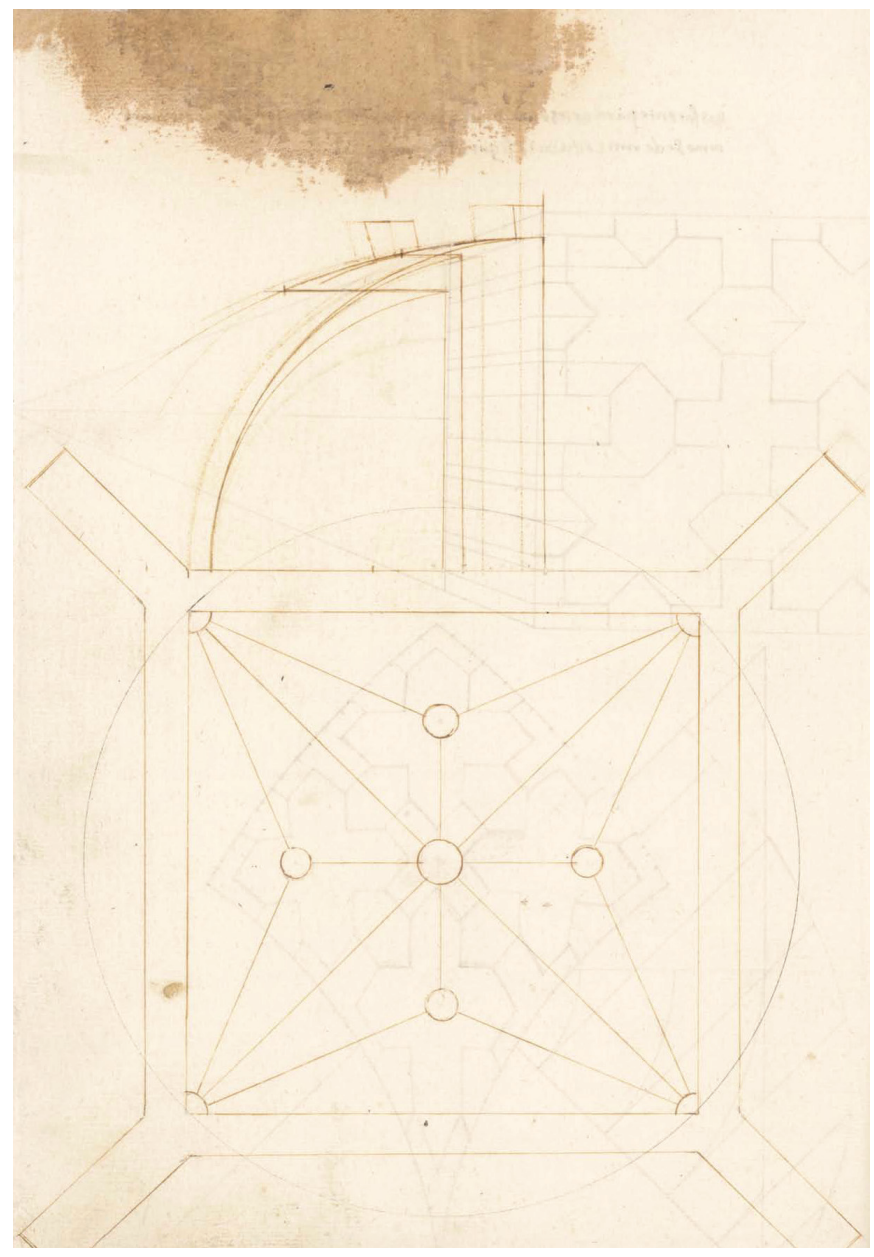

Figura 2. Bóveda de crucería. Hernán Ruiz, Libro de arquitectura, c. 1550.

No parece verosímil que los radios de curvatura de los arcos y, sobre todo, la inclinación de las juntas de lecho de Hernán Ruiz se trasladaran directamente de los dibujos en papel a la obra, entre otras cosas porque los canteros medievales y renacentistas no empleaban el transportador de ángulos, sino un instrumento conocido como saltarregla, similar a un compás sin puntas. Pero además, un pasaje del manuscrito de Rodrigo Gil de Hontañon (1991: 24r$25 \mathrm{v}$ ) señala que se realizaban monteas de bóvedas sobre un andamio " $\tan$ cuajado de fuertes tablones, que en ellos se pueda trazar, delinear, y montear, toda la crucería". Esto es lo que explica que no se hayan conservado los numerosos trazados de bóvedas de terceletes y estrelladas que se debieron realizar durante el gótico tardío según métodos semejantes a los de Hernán Ruiz. Algo parecido ocurre en las complejas Netzgewölbe del gótico tardío germánico: aquí las claves secundarias son múltiples, por lo que se recurre a un arco virtual, el Prinzipalbogen, que corresponde a una serie de tramos de nervios, por lo general de trazado quebrado, y que da la altura de las claves.
Merece la pena señalar que ya en la época gótica los trazados se disponen, bien en lugares apartados del paso, como tribunas o cubiertas planas (Barnes 1972; Claval 1990), bien en estancias específicas como la trasura mencionada en los documentos de la capilla de Saint Stephen en el palacio medieval de Westminster (Hastings 1955: 58-59), o bien directamente debajo de la pieza a ejecutar, con el fin de controlar la ejecución con plomadas, comprobando que los vértices de las piezas caen exactamente sobre su posición teórica en el trazado (Gil de Hontañón 1991: 24v-25r). Estos rasgos se mantendrán en la Edad Moderna, donde se sigue trazando en galerías o espacios bajo escaleras (Taín 2003a; Freire 1998) o en casas de la traza, como las de las catedrales de Sevilla y El Escorial, o debajo de la pieza, como atestigua Alonso de Vandelvira (c. 1580: 23r, 23v) y la montea muy deteriorada de la escalera triple del convento de Santo Domingo de Bonaval (Taín 2006).

La aparición del Renacimiento cambia sustancialmente este panorama. Donde antes se representaban gabletes, rosas o pináculos, ahora se trazan basas, columnas, arcos, frisos, cornisas y frontones (Taín 2003a, 2003b, 2003c, 2009). En el campo de las bóvedas, el cambio es más profundo. Como señaló en su momento Choisy (1899: II-704), se pasa de una concepción de la arquitectura en la que el vocabulario formal deriva de una razón constructiva (aunque la relación sea muy lejana en el gótico tardío) a un esquema completamente diferente en el que se impone a la construcción un sistema formal tomado más o menos literalmente del ejemplo de la Antigüedad. Esto lleva a la sustitución del esquema lineal del gótico por una definición formal basada en superficies o, en términos constructivos, la sustitución de nervios por piezas enterizas.

Estas transformaciones hacen necesario desarrollar, en unas pocas décadas, todo un sistema de transformaciones geométricas para determinar la forma de las plantillas de intradós, lecho y testa de las dovelas de las bóvedas clásicas, y en muchas ocasiones, los ángulos entre aristas de las dovelas, que se venían midiendo con la saltarregla. Es importante tener en cuenta que la plantilla gótica es un dato del problema, elegido por el maestro cantero, mientras que las plantillas renacentistas de intradós o lecho son el resultado de operaciones geométricas como desarrollos, giros o abatimientos. Quizá por esta razón las voces que designan la plantilla gótica, "molde", moule, motlle, dan lugar a "moldura" o moulding al llegar al Renacimiento, mientras que para designar la plantilla renacentista de intradós o lecho es 
necesario crear neologismos como "planta por cara", "planta por lecho", panneau de joinct, panneau de doyle par dessoubz (De L'Orme 1657: 77r; Martínez de Aranda c. 1600; v. Calvo y Ros 2011).

En este nuevo sistema de control formal desempeña un papel central la doble proyección ortogonal, pero sería un error pensar que este sistema de representación era nuevo en sí. La proyección simple, que como hemos visto estaba prácticamente ausente en la Antigüedad, aparece en el cuaderno de Villard de Honnecourt, tanto en planta como en alzado y sección. Por supuesto, lo hace de forma muy rudimentaria, pero esto es la marca de una técnica emergente. Poco a poco va ganando en precisión; en el conocido dibujo del campanario de la catedral de Florencia se incluye un remate octogonal dibujado en correcta proyección vertical que hubiera sido muy difícil dibujar sin el auxilio de una planta. Alberti contrapone el dibujo del arquitecto en proyección ortogonal con la perspectiva de los pintores $(1966,99$; ver también 525, donde habla del trazado de columnas en el suelo; v. Lotz 1956, especialmente el postscript a la traducción inglesa de 1977, recogido también en la española de 1985). Unos años después tanto Piero della Francesca (1942: 32v-43v) como Mathes Roriczer (1486; v. Shelby 1977) y Rafael Sanzio (2003; v. Thoenes 1993; Di Teodoro 2003) exponen cómo construir alzados a partir de plantas; la noción de línea de referencia es todavía confusa, por lo que se emplean reglas, hilos de seda o transferencias a lo largo de perpendiculares para obtener el alzado a partir de la planta. Sólo en algunos esquemas del Underweyssung der Messung de Alberto Durero (1525), como los que se refieren a la sombra del cubo en perspectiva, aparece claramente la línea de referencia que conectan planta y alzado; merece la pena señalar que Durero adscribe esta técnica a los canteros.

Más adelante, en el siglo XVII y sobre todo en el XVIII, estas operaciones geométricas cristalizarán en una disciplina conocida como Estereotomía, esto es, ciencia de la división de los sólidos (Curabelle 1644; De la Rue 1728; Frézier 1737-1739), que se recogerá o dará lugar a un buen número de tratados (además de los citados en el paréntesis anterior, De L'Orme 1567: 56v128v; Rojas 1598: 97r-101v; San Nicolás 1639: 64r-74r, 91r-105v; Desargues 1640; Jousse 1642; Derand 1643; Bosse 1643; Milliet de Challes 1674: 15; Tosca 17071715: 5; De la Rue 1728; Guarini 1737; Frézier 17371739, entre otros). En España este saber no se recogería en un volumen completo hasta la época del padre Tosca; esta situación daría lugar a la circulación, por supuesto más restringida, de una serie de manuscritos canteriles (Manuscrito anónimo de cantería c. 1540; Alonso de Guardia c. 1600; Manuscrito anónimo de cantería, $c$. 1650; Portor 1708; Tornés c. 1700; Fernández Sarela 2014) que recogen la práctica constructiva de una forma más directa que algunos manuscritos franceses, influenciados por De L'Orme (Chéreau c. 1570), y que dos textos españoles destinados a la publicación; Vandelvira 1977; Martínez de Aranda 1986).

En cualquier caso, algunos pasajes de estos tratados y manuscritos, como el pasaje citado de Gil de Hontañón y una frase de Vandelvira (1977: 23r) que señala que la planta "ha de estar echada en el suelo a nivel y como se fueren asentando las piezas del arco se han de ir aplomando con ella" indican que en realidad los dibujos en papel de estos textos canteriles no hacen más que representar con fines didácticos los trazados a tamaño natural que se exponen en tratados y manuscritos. Una excepción confirma la regla; se conserva en el archivo de la catedral de Segovia un dibujo que representa el trazado de las plantillas de dos bóvedas de naranja, probablemente la del cimborrio catedralicio y su linterna. El método empleado coincide punto por punto con el propuesto en la gran mayoría de los tratados y manuscritos de cantería, empezando por De L'Orme (1567: 112v-115v) y Vandelvira (1977: 60v), que por otra parte se emplea en monteas de las terrazas de la catedral de Sevilla y la parroquial de Carnota (Ruiz de la Rosa y Rodríguez 2002; Taín 2006; Taín y Natividad 2011). Ahora bien, los errores e indecisiones del dibujo, que hemos analizado en otro lugar (Alonso, Calvo y Rabasa 2009), sugieren que si el autor se molestó en preparar la traza en papel y no abordó directamente la montea, es porque dudaba de su propia competencia para este trabajo.

En cualquier caso, sería un error considerar que todos los trazados arquitectónicos a tamaño natural de la Edad Moderna tienen por finalidad resolver problemas de estereotomía de la piedra. En primer lugar, se han hallado algunos trazados relacionados con construcciones de albañilería (Sebastiá 2011: 1316-1317). En segundo lugar, entre los muy numerosos trazados hallados en Galicia, sólo tres grupos, los correspondientes a la escalera de Santo Domingo de Bonaval, las bóvedas de horno de Carnota (fig. 3) y un capialzado en el convento de Santa Clara de Santiago, abordan piezas que plantean problemas de estereotomía complejos, y entre ellos el único que incluye explícitamente las construcciones necesarias para la obtención de plantillas es el de Carnota (Taín 2006, 2009; Calvo y Taín 2015). 

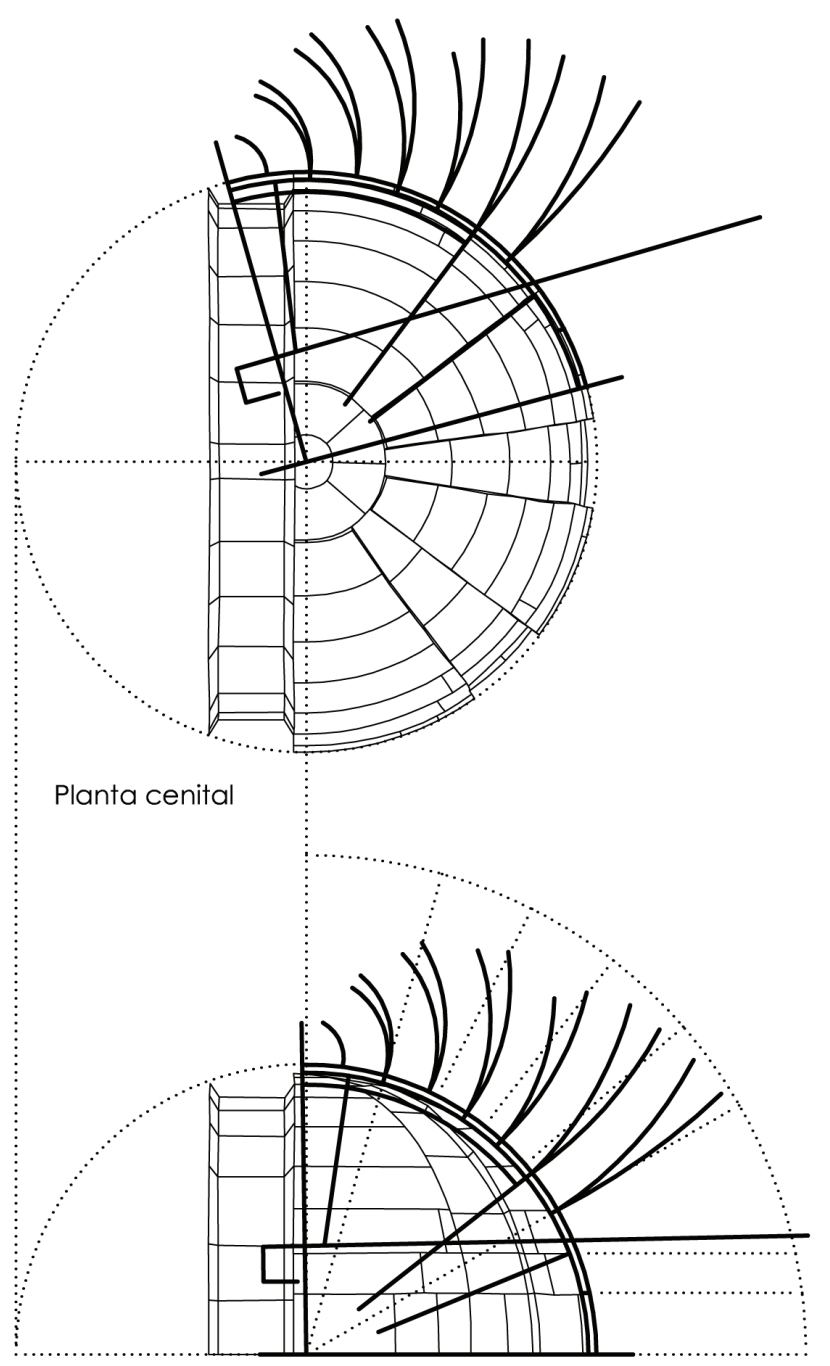

Sección transversal

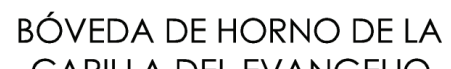

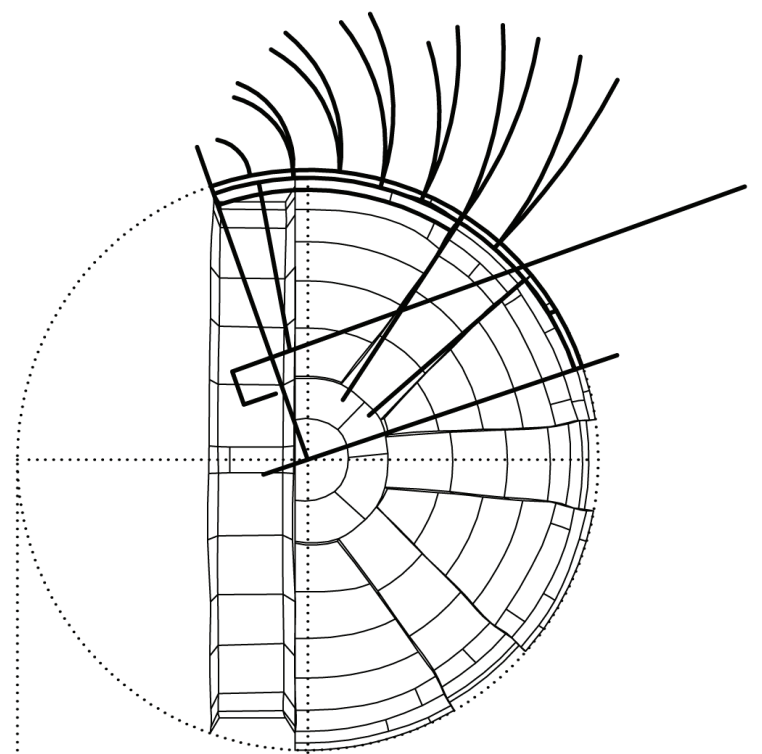

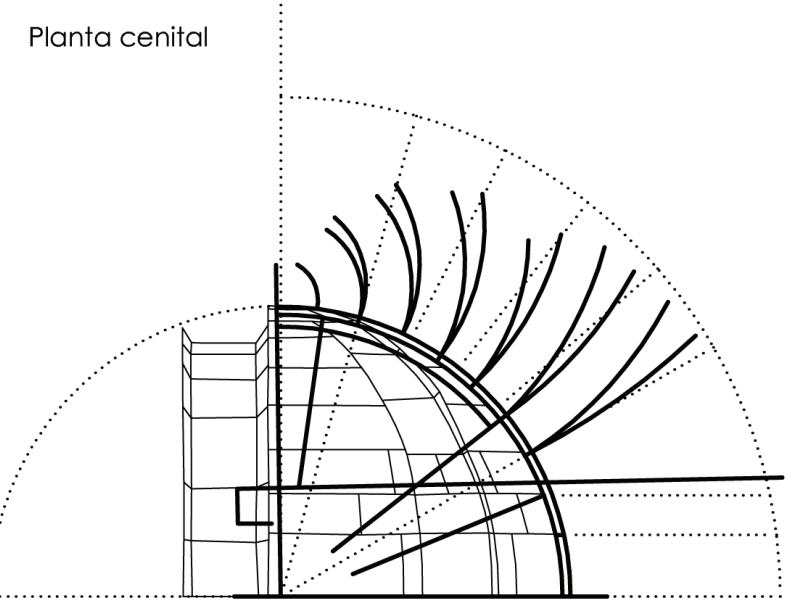

Sección transversal

\section{BÓVEDA DE HORNO DE LA CAPILLA DE LA EPÍSTOLA}

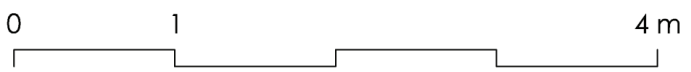

Figura 3. Montea para las bóvedas de horno de la parroquial de Carnota, superpuesta a las bóvedas de horno de las naves de la epístola y el evangelio.

Aún así, la estereotomía desempeñó un cierto papel en la última y decisiva evolución de esta técnica. Gaspard Monge, profesor de Teoría del Corte de las Piedras en la escuela de ingenieros militares de Mezières, transformó la práctica de la doble representación ortogonal de los canteros en una ciencia nueva y vieja, la geometría descriptiva, que mantuvo en secreto mientras estuvo en Mezières y explicó con gran resonancia en dos escuelas revolucionarias que darían lugar a cientos de émulas: la École Normale y la École Polytechnique
(Monge 1798; Taton 1950, 1954; Sakarovitch 1992, 1995, 1997). En aquella época el término épure, que se aplicaba desde tiempo inmemorial a los trazados a tamaño natural de los canteros, pasa a designar los ejercicios en papel de los aspirantes de ingeniero. A partir de ese momento, los trazados a tamaño natural pasan a ser replanteos, derivados de los dibujos en papel, invirtiendo la primacía de las monteas que se puede percibir en los tratados y manuscritos de cantería y sobre todo, en el dibujo de Segovia. 


\section{LOS TRAZADOS A TAMAÑO NATURAL COMO FUENTE MATERIAL DE LA HISTORIA DE LA ARQUITECTURA Y DE LA CONSTRUCCIÓN}

Los trazados a tamaño natural pueden ofrecer una información muy valiosa acerca de los procesos de ejecución de las construcciones a lo largo del arco temporal que hemos definido en la sección anterior. En comparación con la atención suscitada por las marcas de cantero, que aportan ante todo indicios de autoría de una forma indirecta, resulta llamativo que el estudio de los trazados de cantería haya suscitado interés únicamente en círculos minoritarios.

En primer lugar, la confrontación de los trazados con los métodos geométricos incluidos en tratados y manuscritos permite calibrar hasta qué punto los textos de la cantería recogían la verdadera práctica a pie de obra o la adornaban con intenciones didácticas, como ocurre en ocasiones con los manuales de nuestros días. Por ejemplo, entre el gran número de trazados de la iglesia conventual de Santa Clara de Santiago, hallados en 2014, se encuentra el del capialzado esviado de la portería del convento (fig. 4), similar a los incluidos en los manuscritos de Ginés Martínez de Aranda (c. 1600: 150-154) y Juan de Portor y Castro (1708: 28v), dos maestros vinculados a la ciudad. Ahora bien, las sofisticadas plantillas de
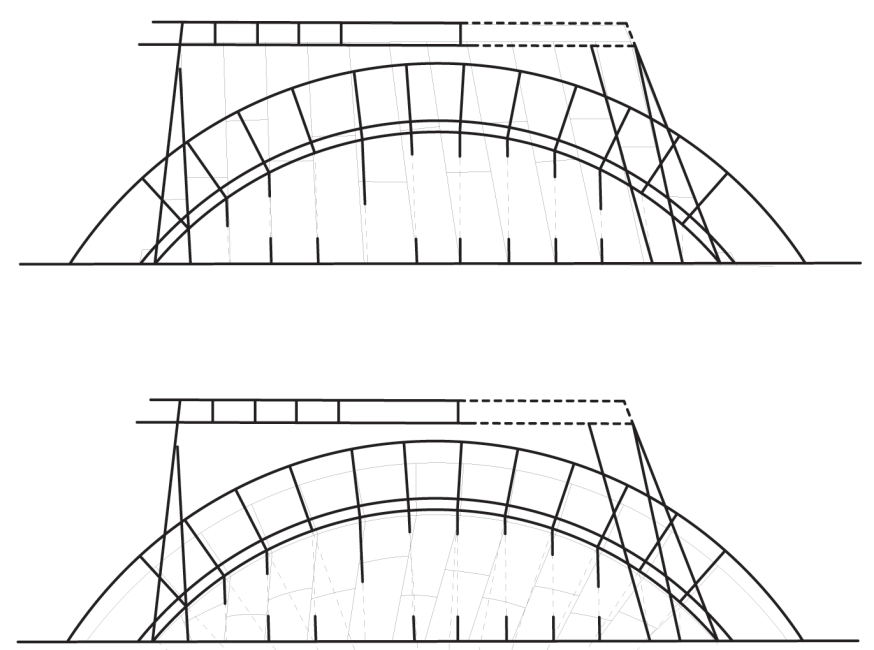

0 $1 \mathrm{~m}$

Figura 4. Trazado para el capialzado oblicuo de la portería de Santa Clara de Santiago, superpuesto al capialzado construido. superficies alabeadas incluidas en ambos manuscritos brillan por su ausencia en la montea operativa de la iglesia; esto nos hace sospechar que ambos tratados presentan, al menos en estas trazas, prácticas de vanguardia que no se empleaban con frecuencia en la labor diaria.

Al mismo tiempo, la comparación de las monteas con los tratados y manuscritos permite precisar el momento de aparición de los métodos geométricos empleados en unos y otros e, indirectamente, el progreso de los conocimientos geométricos de los canteros. Por ejemplo, la técnica de obtención de plantillas de bóvedas esféricas basada en desarrollos de conos, presente en De L'Orme (1567: 111v-115r) y más claramente en Vandelvira (1700: $60 \mathrm{v}$ ), aparece ya en una montea de las terrazas de la catedral de Sevilla, datada por Ruiz de la Rosa y Rodríguez (2002) en 1546. Ahora bien, en dos ejemplos comparables, la bóveda de la sacristía de la catedral de Murcia (fig. 5), fechada en 1525, y la montea de la capilla de Junterón, que se puede datar entre esta fecha y 1543, las plantillas brillan por su ausencia (Calvo, Alonso, Rabasa y López 2005; Calvo, Molina, Alonso, López, Rabasa, Pozo y Sánchez 2010; Calvo, Molina, Natividad, Alonso, Rabasa, López, Taín y Sánchez 2013a). En principio, esto permite situar la aparición de la técnica en Sevilla algo antes de 1546 , pero también hay que tener en cuenta que la bóveda murciana lleva gallones cuidadosamente dispuestos, mientras que la capilla de Junterón incluye una decoración muy rica; podría ocurrir que la renuncia al

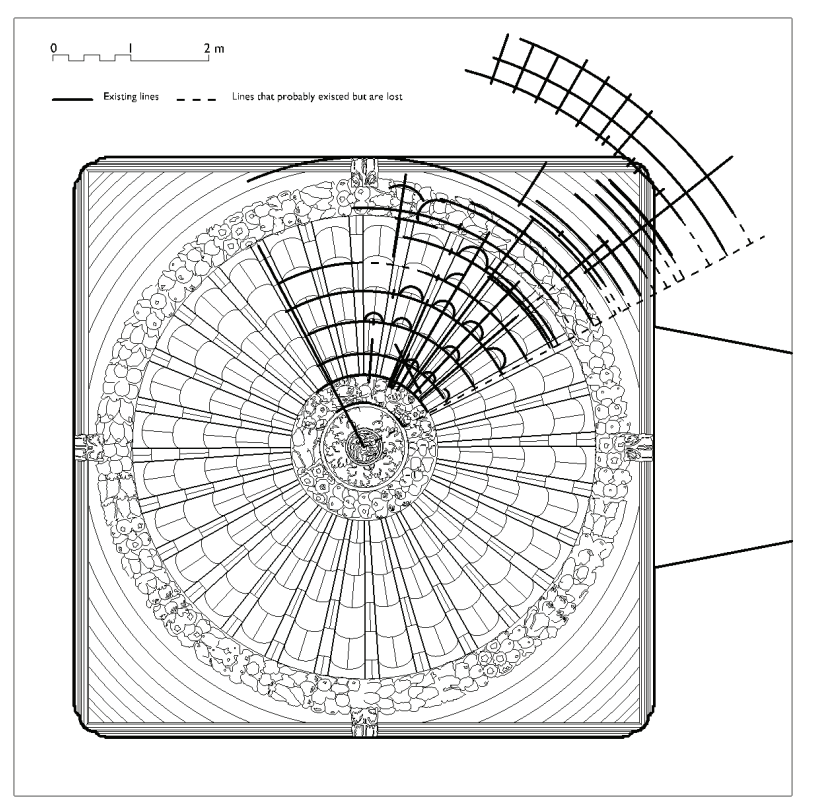

Figura 5. Montea para la bóveda de la sacristía de la catedral de Murcia, superpuesta a la bóveda construida. 
empleo de plantillas fuera voluntaria, con objeto de labrar la pieza por escuadría para controlar mejor la ejecución de gallones y decoración. Sólo futuros hallazgos permitirán resolver definitivamente esta cuestión.

Hasta ahora, estas dos formas de explotación de los trazados a tamaño natural no exigen su documentación por métodos especialmente precisos. Ahora bien, la confrontación entre trazados y piezas suministra una información muy valiosa a la hora de conocer la evolución constructiva de un determinado edificio. Como es obvio, esto exige la medición tanto de la obra construida como del trazado con la máxima precisión posible, idealmente con errores de pocos milímetros; los métodos para hacer esto, que se recogen en los dos apartados siguientes, son el núcleo de este artículo. Además, puesto que por lo general las monteas representan elementos de un edificio en planta, alzado o ambas, es necesario obtener una representación de la obra construida en proyección ortogonal.

En primer lugar, la comparación de monteas y obra construida permite confirmar o descartar la identificación del referente de las monteas en muchos casos. En ocasiones, el referente del trazado es inequívoco, como en la montea de la coronación del edificio de la portería del convento de Santa Clara (Calvo y Taín 2015) (fig. 6 ); en otras no lo es tanto, en particular cuando nos encontramos con situaciones en las cuales se ha modificado el diseño sobre la marcha.

En cualquiera de los dos casos, la superposición de montea y proyección ortogonal del edificio permite calibrar la precisión de la ejecución y al mismo tiempo determinar si se han introducido voluntariamente variaciones del diseño entre la realización del trazado y la ejecución material del elemento al que se refiere. En principio, se trata de dos cuestiones distintas: precisión y fidelidad. En algunos casos, como la sacristía de la catedral de Murcia, el capialzado de Santa Clara de Santiago, la coronación de la fachada de este convento, o las bóvedas de Carnota (fig. 5, 4, 6, 3), la coincidencia entre montea y pieza, es llamativa, con errores no mayores de algunos centímetros, que se pueden entender como tolerancias de construcción plenamente aceptables, no ya en la Edad Moderna, sino incluso en obras de edificación ordinarias de nuestros días (Calvo, Molina, Natividad, Alonso, Rabasa, López, Taín y Sánchez 2013a; Calvo y Taín 2015; Taín y Natividad 2011).

Ahora bien, la precisión no excluye la introducción de modificaciones en el momento en que se ejecutaron los trabajos; las hemos encontrado en la práctica totalidad de las obras analizadas, con la excepción de la sacristía de Murcia. En el capialzado de Santa Clara de Santiago (fig. 4), la planta, el número de dovelas y la disposición del batiente coinciden con el trazado con tolerancias de pocos centímetros, pero el ancho de la rosca se reduce en aproximadamente $10 \mathrm{~cm}$, que ya no podemos justificar por tolerancias, ni tampoco por deformaciones mecánicas del elemento constructivo. Lo contrario ocurre en la coronación de la fachada, donde se aumenta la altura en unos $25 \mathrm{~cm}$, medida próxima a un pie (fig. 6); es significativo que las partes superiores e inferiores de este elemento coinciden sustancialmente con la montea, mientras que las partes intermedias, en particular algunas volutas, se alargan para obtener el aumento de altura buscado (Calvo y Taín 2015). Todo esto parece responder a un deseo de utilizar en la mayor medida posible la montea y probablemente las plantillas preparadas partiendo de ella, que parece fueron realizadas antes de decidir el alargamiento.

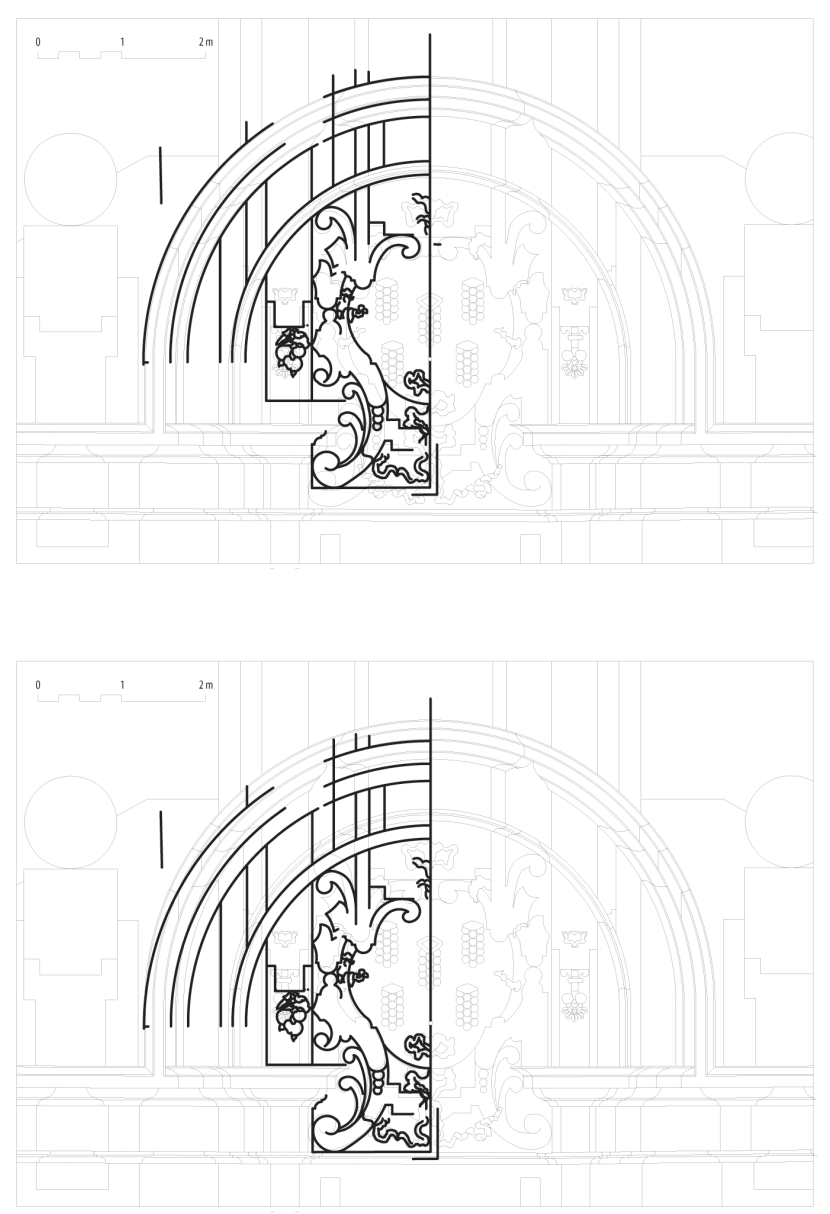

Figura 6. Montea para la coronación de la fachada de la portería de Santa Clara de Santiago, superpuesta a la fachada construida. 
En otros casos, las modificaciones del diseño son graduales. En Carnota (Taín y Natividad 2011), la bóveda de horno situada a los pies de la iglesia, en la nave del evangelio, coincide en diseño y dimensiones con uno de los trazados. Ahora bien, al ejecutar la bóveda se decidió emplear piezas más grandes que las previstas al realizar el trazado, por lo que el número de hiladas de la pieza terminada es menor que las reflejadas en la montea (fig. 3). El trazado se emplea también en la bóveda de horno de la nave de la epístola, pero aquí, además del número y tamaño de las hiladas, se modifica la forma de los gallones, que pasan a ser de lados paralelos, frente a la disposición radial de la bóveda del evangelio y la montea.

En otras ocasiones, las diferencias entre el trazado y la pieza ejecutada parecen responder a una simplificación deliberada. A simple vista o con mediciones sencillas, se aprecia que el trazado existente en el pavimento de la capilla de Santa Catalina de la catedral de Tui (fig. 7) corresponde a las bóvedas nervadas de la sacristía catedralicia, tanto en disposición general como en dimensiones (Taín, Alonso, Calvo y Natividad 2012). La medición de trazado y bóvedas con estación total revela que las bóvedas construidas presentan un cierto esviaje, mientras que en el trazado las ligaduras son ortogonales entre sí, dentro de las tolerancias usuales. Teniendo en cuenta que las bóvedas originales son de finales del siglo XV y el pavimento de la capilla de principios del XVIII, la única interpretación posible es que la montea se preparó para una reforma dieciochesca de las bóvedas tardomedievales. Los ejecutores de la reforma prefirieron representar en la montea un trazado ideal, que luego adaptaron como pudieron a la planta esviada de la sacristía; lo confirman los arcos trazados para computar el radio de los nervios, que son coherentes con el trazado ideal, pero no con la geometría de la bóveda oblicua.

En otros muchos casos, las coincidencias entre trazados y piezas construidas se reducen a algunos datos básicos, como las luces de arcos o bóvedas, pero la disposición general es claramente diferente. En un principio, se puede pensar que se ha abandonado por completo el diseño y los constructores han optado por improvisar en la ejecución; esta hipótesis resulta sostenible en casos como el de la capilla de San Pedro González Telmo en Tui (fig. 8, 9), entre otras razones porque coincide con la accidentada historia constructiva de este santuario, recogida en documentos de archivo (Calvo, Alonso, Taín y Natividad 2013b).

Ahora bien, el reciente hallazgo de los trazados de la iglesia conventual de Santa Clara de Santiago

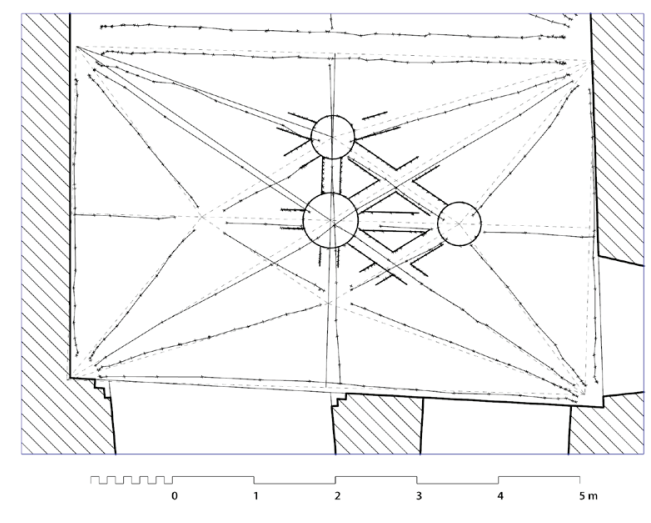

Figura 7. Trazado de bóveda de cantería en la capilla de Santa Catalina de la catedral de Tui, superpuesta a las bóvedas construidas.

sugiere una interpretación diferente (Calvo y Taín 2015). Encontramos aquí en ocasiones varios trazados para un mismo elemento, como el capialzado esviado o el nicho de Santa Clara que ocupa el centro de la fachada; algunos coinciden con el elemento construido únicamente en los datos básicos como luces o flechas, otros presentan semejanzas más marcadas en datos como radios, y por último otros coinciden con fidelidad casi total, como hemos visto para el capialzado (fig. $10,11,4)$. Esto plantea una posibilidad de gran interés: podemos entender que las monteas de este convento no son exclusivamente dibujos de ejecución, como se ha venido entendiendo hasta ahora, sino que desempeñan una función análoga a los bocetos en papel en el proceso de diseño. Esta hipótesis es hoy por hoy de difícil comprobación. Habrá que esperar a que aparezcan otros conjuntos de monteas tan extensos y complejos como el de Santa Clara para determinar si se repite la presencia de varios trazados para un mismo elemento. Mientras tanto, un detalle parece apuntar en la misma dirección, poniendo a los trazados a tamaño natural en una posición comparable a los dibujos en papel. Se conserva en el archivo conventual de San Francisco de Santiago una traza atribuible a Fray Ignacio de Fontecoba para una obra indeterminada, que muestra una clara semejanza con la coronación de la portería de Santa Clara (fig. 6, 12). Pero lo más llamativo es que la traza de San Francisco representa únicamente la mitad izquierda del remate, como la mayor parte de las monteas de la iglesia conventual, y por tanto, podría derivar directamente de la montea y no tanto de la obra construida ni de una traza en papel (Vigo 2011: 522; 


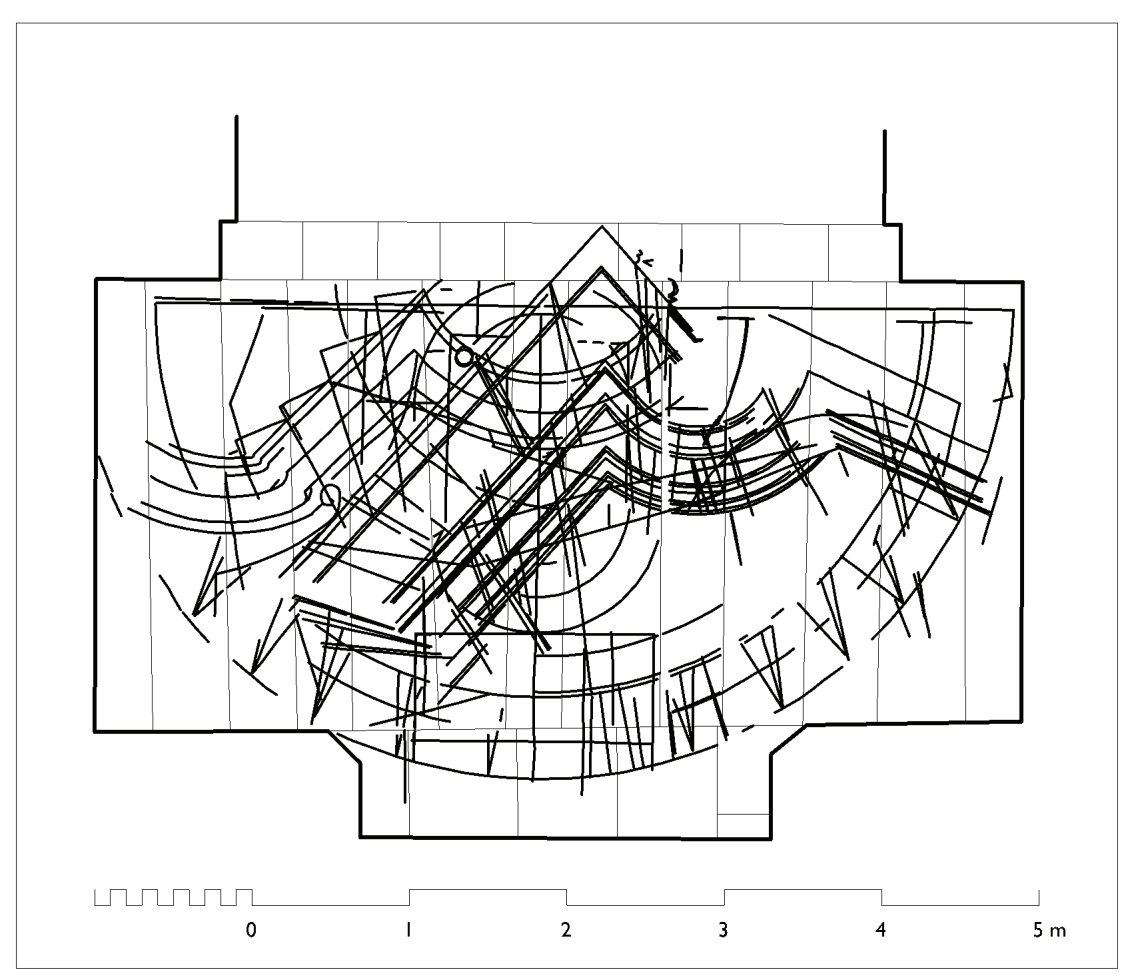

Figura 8. Monteas en el coro alto de la capilla de San Telmo de Tui.

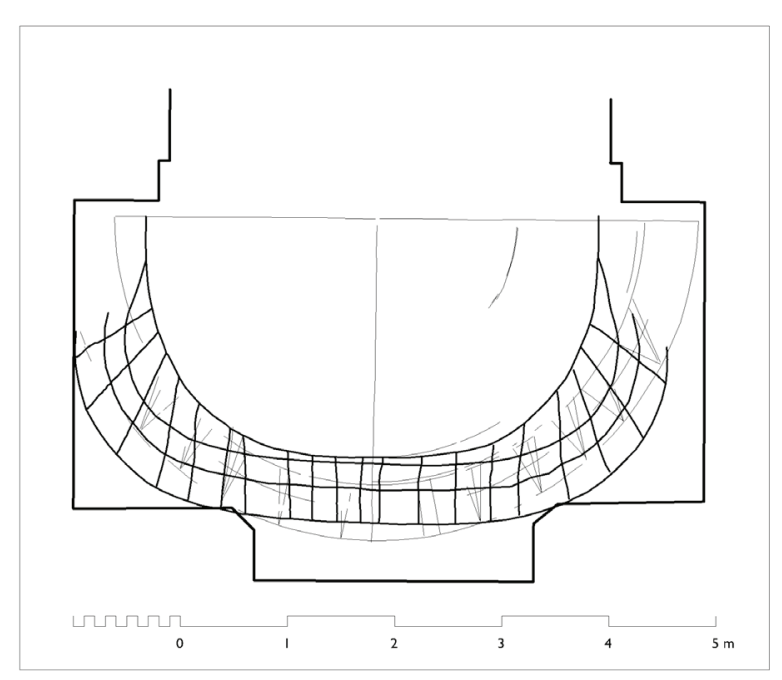

Figura 9. Montea para un arco en el coro alto de la capilla de San Telmo de Tui, superpuesta al arco central de la fachada.

Pita 2014). Tendríamos por tanto un dibujo a escala derivado de un trazado a tamaño natural, lo que pone unas fuentes y otras al mismo nivel y desmiente la consideración exclusiva de las monteas como dibujos de ejecución.

Vemos por tanto, que incluso con el reducido número de ejemplos analizados hasta la fecha, los trazados a tamaño natural pueden ofrecer datos valiosos acerca de las circunstancias de ejecución, y en ocasiones de diseño, de las obras de arquitectura y de la personalidad de sus protagonistas; pueden ayudar a valorar en su justa medida los tratados y manuscritos constructivos, precisando en qué medida se siguen en la práctica; y en último término permiten valorar los conocimientos científicos y constructivos de arquitectos y artífices. Por supuesto, como hemos visto en algún caso, estas fuentes de la cultura material deben emplearse en conjunción con las fuentes tradicionales de la historia de la arquitectura, como los documentos de archivo, los tratados y manuscritos, los dibujos en papel y sobre todo, los propios monumentos.

\section{MÉTODOS DE LEVANTAMIENTO DE TRAZADOS A TAMAÑO NATURAL}

\section{Métodos de calco manual}

En un primer momento, los trazados a tamaño natural hallados en la catedral de Sevilla, en la capilla de Junterón de Murcia (fig. 13), en numerosas localizaciones gallegas (fig. 14, 15) o en los sótanos de El Escorial fueron documentados mediante calco, empleando en algunos casos 


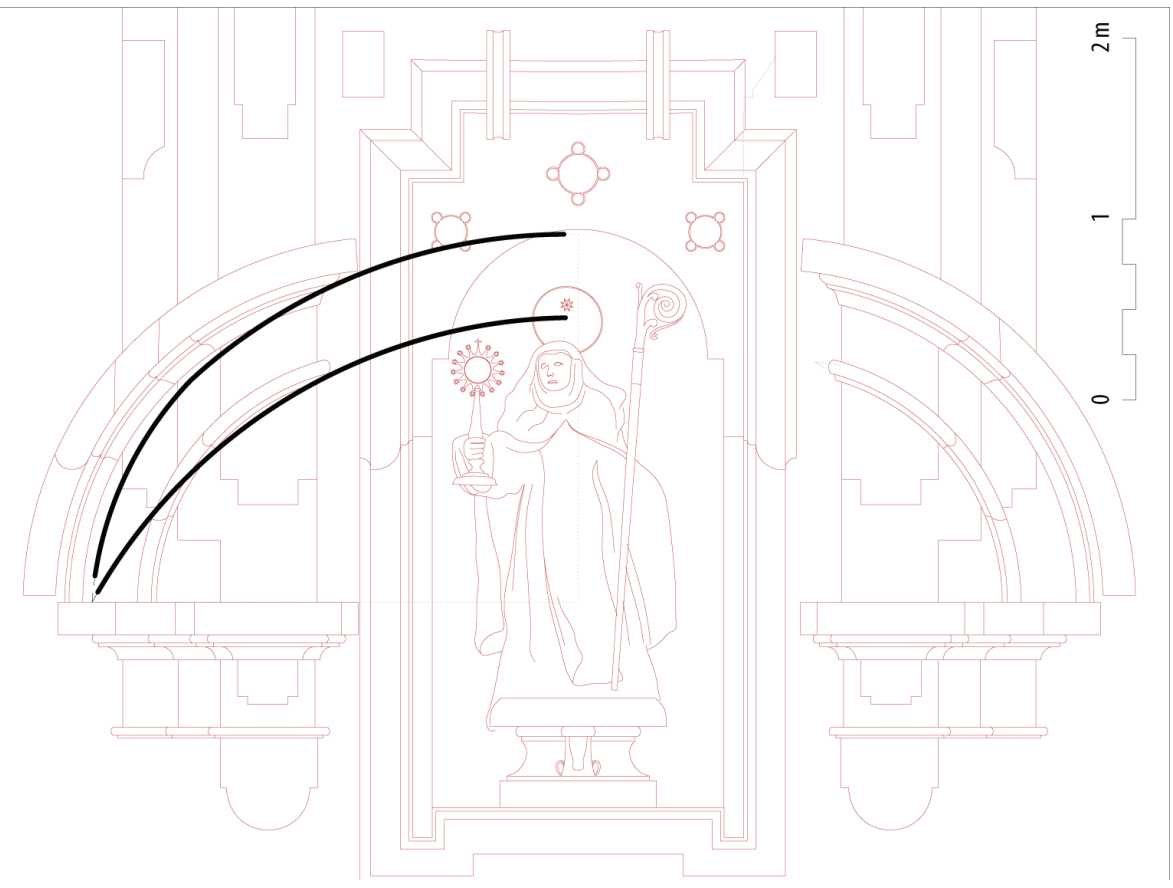

Figura 10. Montea para un capialzado en la iglesia conventual de Santa Clara de Santiago, superpuesta al nicho de Santa Clara de la fachada de dicho convento. rollos de papel de croquis o láminas de acetato. Con objeto de facilitar la localización de los trazados bajo el papel, se ha empleado en ocasiones tiza, pintura reversible o cinta adhesiva, que no deterioran la obra original (Ruiz de la Rosa y Rodríguez 2002; Calvo, Alonso, Rabasa y López 2005; Calvo, Molina, Alonso, López, Rabasa, Pozo y Sánchez 2010; Taín 2003a, 2006). Estos métodos ofrecen una precisión aceptable, pues el error cometido al marcar el trazado en el papel no excede de algunos milímetros. Sin embargo, cuando nos planteamos su cambio de escala

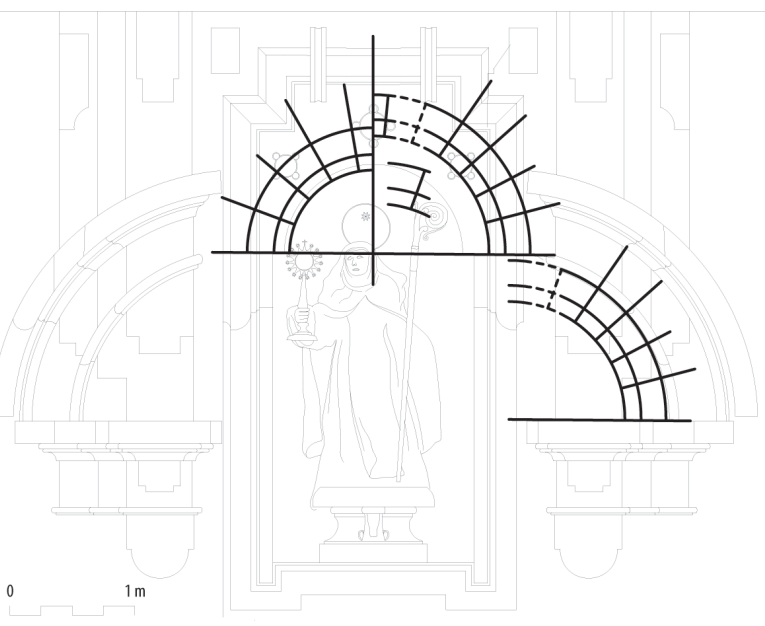

Figura 11. Monteas de la iglesia conventual de Santa Clara de Santiago, superpuestas al nicho de Santa Clara de la fachada de dicho convento.

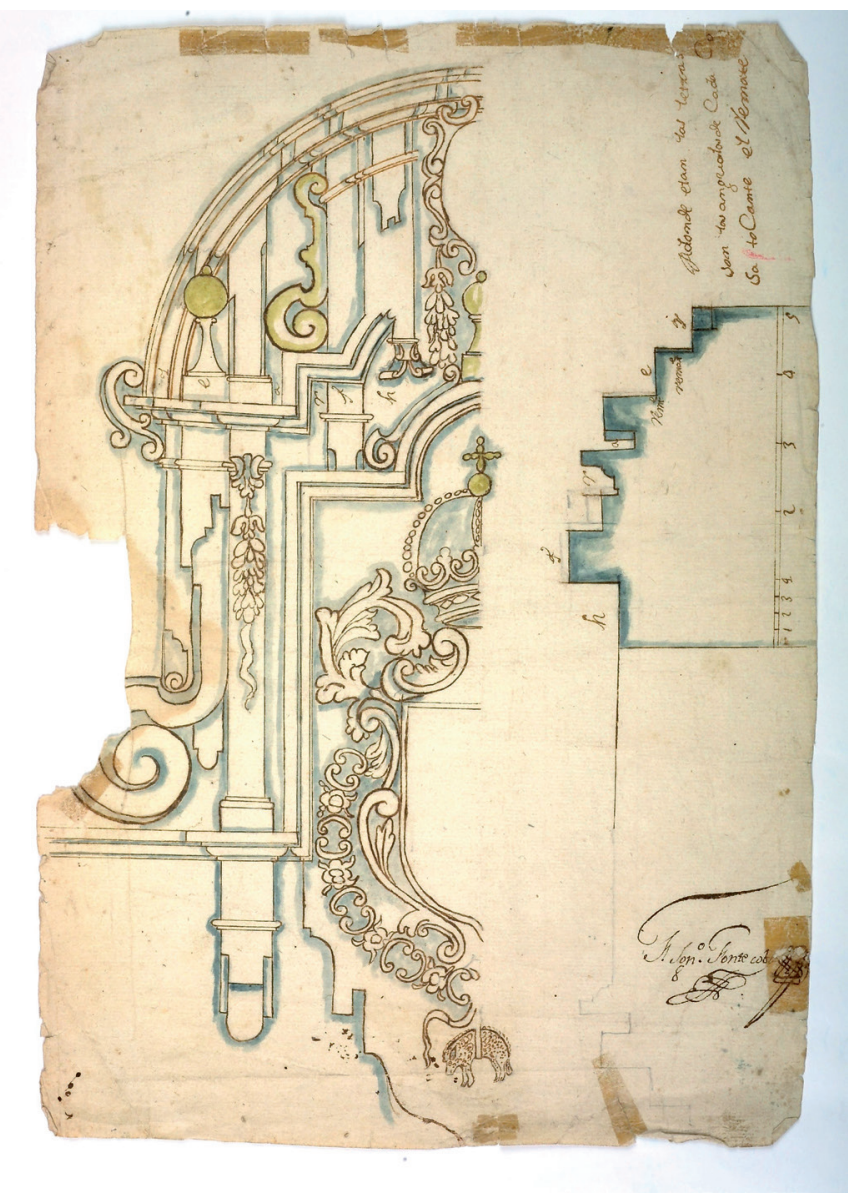

Figura 12. Traza de Fray Ignacio de Fontecoba para una obra indeterminada. Archivo del Convento de San Francisco de Santiago de Compostela. 
o digitalización para la presentación de los resultados, es preciso emplear técnicas de triangulación que pueden introducir errores mayores.

\section{Métodos basados en el empleo directo de la estación total}

Para evitar estos problemas, se han venido empleando métodos alternativos que ofrecen directamente un dibujo vectorial de los trazados. Al analizar el trazado de la sacristía de la catedral de Murcia, inscrito en uno de los muros de la estancia, se empleó un método basado en la actuación de tres operadores (Calvo, Molina, Natividad, Alonso, Rabasa, López, Taín y Sánchez 2013a). Uno de ellos permanecía junto al trazado, iluminando con una linterna puntos concretos de la montea, mientras otro operador tomaba coordenadas de puntos con una estación total láser Leica TCR 1005, que ofrece una precisión nominal de $3 \mathrm{~mm}$ en las coordenadas de los puntos medidos a menos de $30 \mathrm{~m}$, como es el caso.

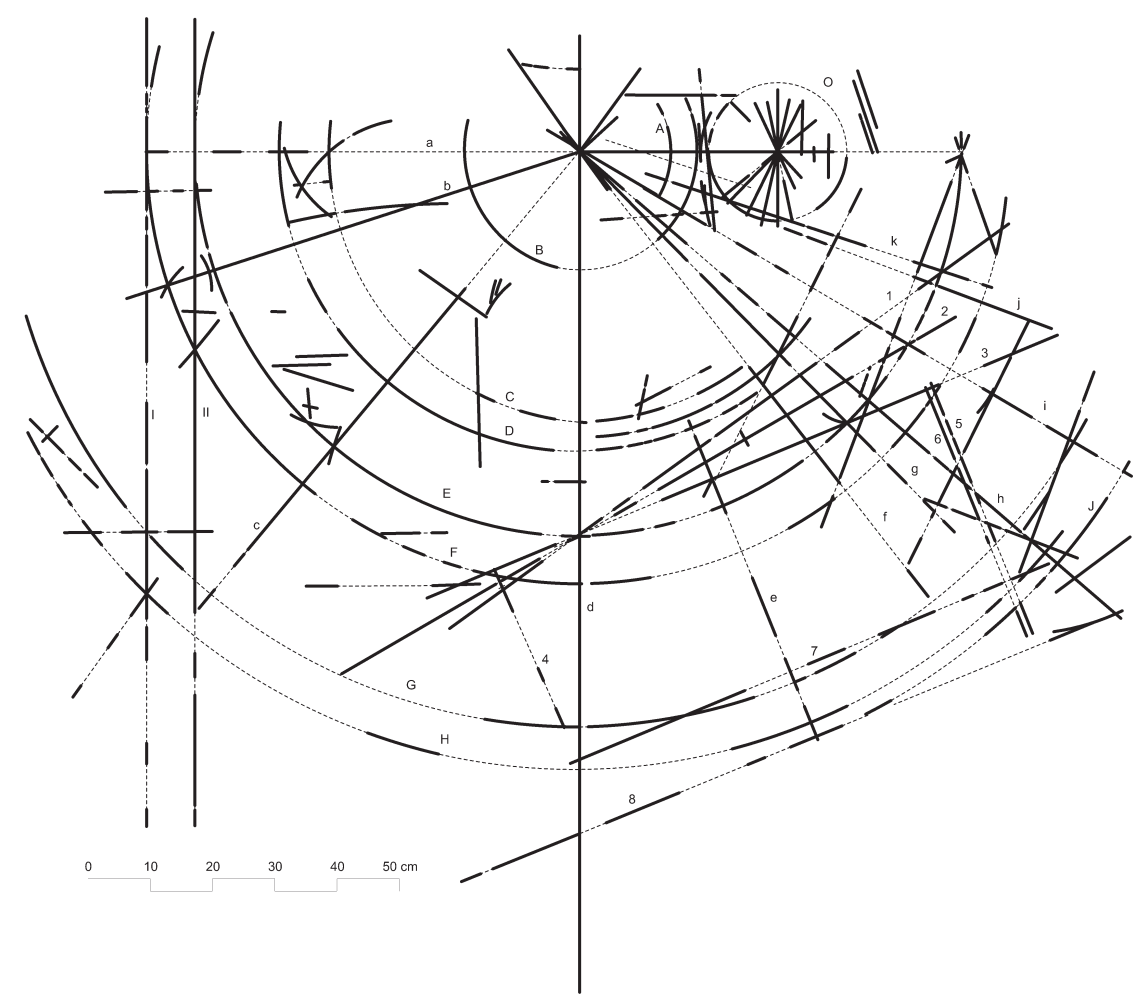

Figura 13. Montea en la capilla de Junterón de la catedral de Murcia.

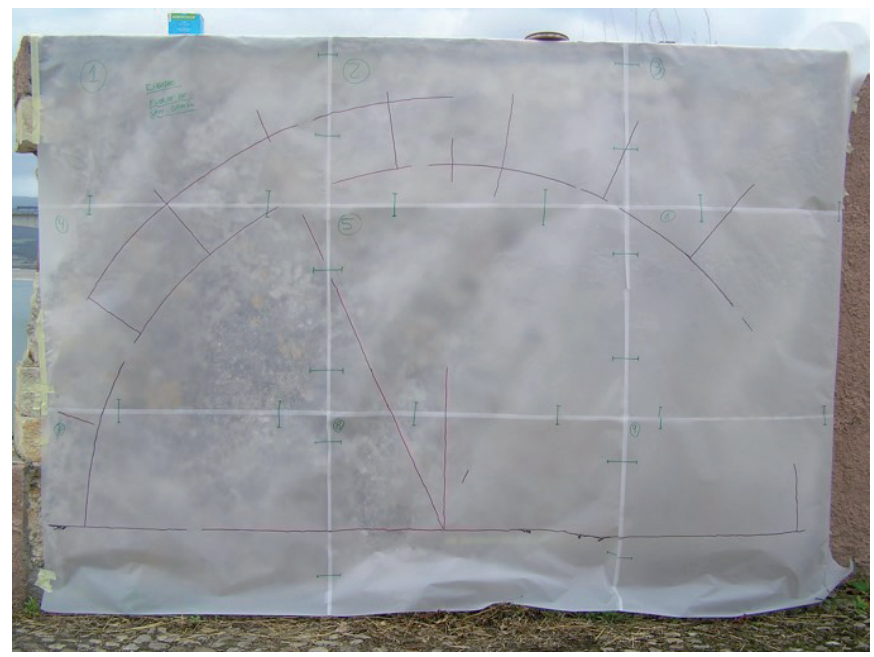

Figura 14. Calco de una montea en el castillo de San Damián de Ribadeo.

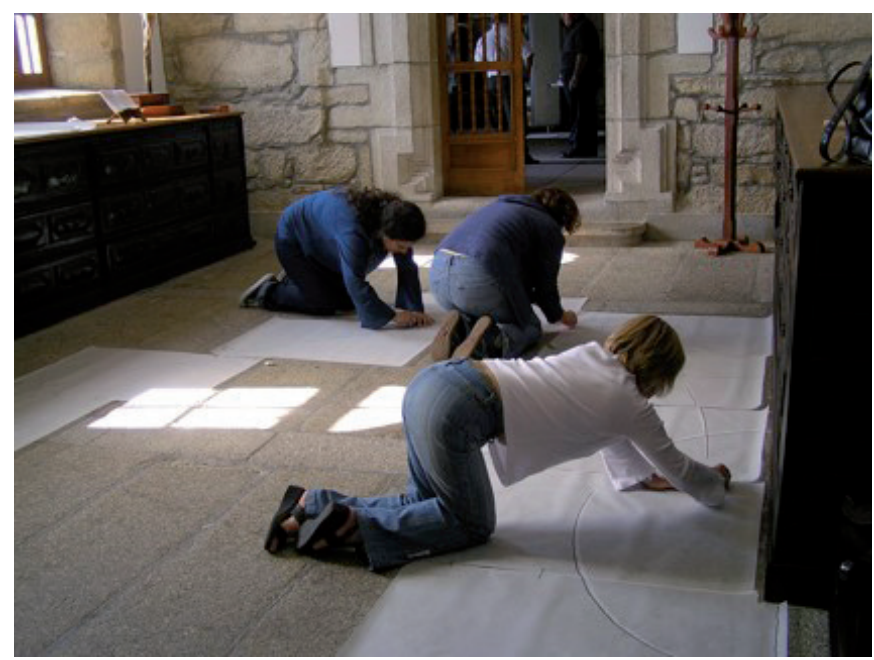

Figura 15. Calco de una montea en la sacristía de la iglesia conventual de San Francisco en Tui. 
Ahora bien, el producto de esta operación es una simple nube de puntos que no refleja el trazado de una forma inteligible a menos que se añadan los segmentos de recta y arcos que unen los puntos entre sí. Para evitar los errores que pueden cometerse en esta fase, un tercer operador tomó fotografías con una cámara Canon 5D Mark II, con 21,0 Mpx de resolución y un objetivo EOS 70-200 mm, montada sobre trípode. Se tomaron dos series, una primera de 9 fotografías tomadas con longitud focal de $70 \mathrm{~mm}$ para dar una visión por zonas relativamente grandes, y otra segunda, de 83 fotografías a $200 \mathrm{~mm}$, para obtener el máximo detalle (fig. 16). A continuación se procesaron estas fotografías en blanco y negro y con un contraste elevado, con objeto de favorecer la localización de cualquier línea del trazado; es preciso tener en cuenta que en este método la definición de las líneas del trazado depende exclusivamente de estas series de fotografías, pues la estación total ofrece únicamente puntos. Se puede argumentar en contra que las recientes estaciones totales, dotadas de cámaras digitales, o la multiestación Leica Nova MS 50, permiten superar estas limitaciones, pero sus prestaciones son claramente inferiores a las de una cámara fotográfica digital propiamente dicha.

Por el contrario, la experiencia demostró que el método era eficaz, pues permitía unir los puntos con seguridad, obteniendo una precisión elevada, que en este caso era muy importante; como veremos después, se trataba de afinar un levantamiento previo, que sugería que la construcción había reproducido el trazado con una precisión más que notable para la época (fig. 5).

El mismo método se empleó en la documentación del trazado de la capilla de Santa Catalina de la catedral

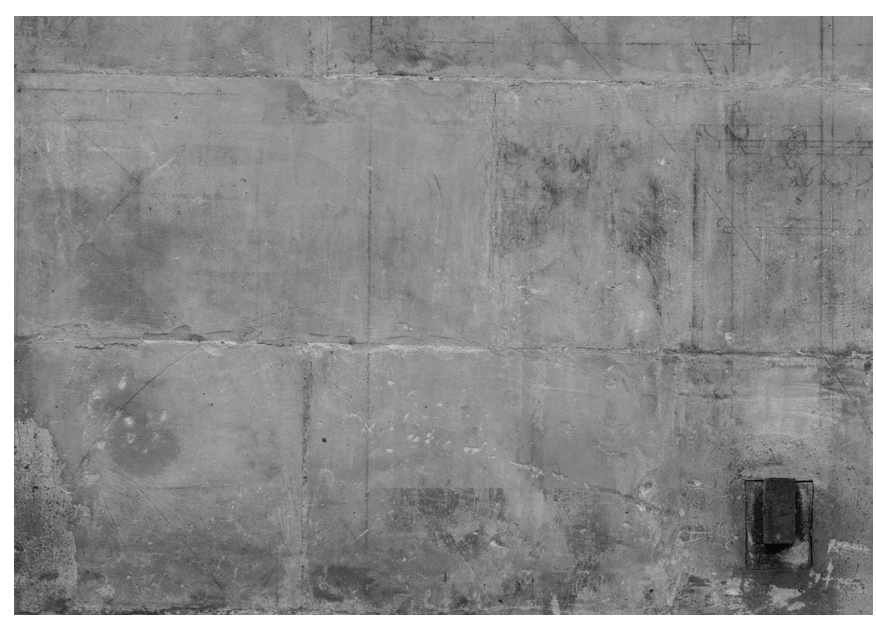

Figura 16. Fotografía de detalle de la montea de la sacristía de la catedral de Murcia. de Tui (Taín, Alonso, Calvo y Natividad 2012), que como hemos visto representa las bóvedas de crucería de la sacristía catedralicia, con algunas variantes en función de las circunstancias de toma (fig. 1, 7). Por una parte, la iluminación de la sala, destinada ahora a museo, hizo innecesario el empleo de linterna. Por otra parte, al estar realizado el trazado en el suelo, se empleó un trípode especial cuya columna central se puede disponer en posición horizontal, junto con un objetivo descentrable TS-E $24 \mathrm{~mm}$, lo que permite obtener fotografías del pavimento evitando la obstrucción de las patas del trípode, cubriendo cada una de ellas un área de aproximadamente $1,5 \mathrm{~m}$ por $1 \mathrm{~m}$. La pequeña dimensión del conjunto, de $6,36 \mathrm{~m}$ por $4,10 \mathrm{~m}$, hace que el ángulo de incidencia del rayo láser de la estación en el pavimento no sea excesivamente agudo, por lo que no plantea problemas de precisión sustanciales.

Sin embargo, como veremos, existen limitaciones para la aplicación de este método en conjuntos extensos o complejos, debidas tanto al problema de la incidencia del rayo láser en ángulos agudos, como a la posibilidad de errores al conectar puntos o al tiempo de trabajo necesario para tomar un alto número de puntos. Todo esto ha llevado a emplear otros métodos, cada uno con sus ventajas e inconvenientes.

\section{Métodos basados en rectificación fotográfica}

Estos métodos se basan en la rectificación de fotografías digitales, sometiendo bien a la fotografía, bien a un dibujo calcado digitalmente sobre ella, a una transformación homográfica con objeto de conseguir que el dibujo final represente en verdadera forma el plano del muro o pavimento sobre el que se inscribe el trazado. Como hemos dicho antes, en la sacristía de Murcia se realizó un levantamiento previo basado en la rectificación de una fotografía del trazado, por el equipo AeroGraph Studio, contratado para realizar esta y otras tareas con cargo al proyecto de restauración de la cajonería de la sacristía. Al superponer el dibujo obtenido a partir de la fotografía rectificada con un levantamiento anterior de la bóveda realizado mediante estación total, se apreció que la coincidencia entre uno y otro era verdaderamente notable, con errores máximos de $6 \mathrm{~cm}$; pero también quedó claro que estos errores aumentaban de forma notable hacia la periferia de la imagen. Ambas circunstancias, la convicción de que nos hallábamos ante un caso excepcional de coincidencia de trazado y obra construida, y la sospecha de que podía obtenerse mayor precisión con otros métodos, 
nos llevó a emplear el método basado en estación total que hemos descrito en el apartado precedente (Calvo, Molina, Natividad, Alonso, Rabasa, López, Taín y Sánchez 2013a).

Todo esto no nos ha llevado a descartar los métodos basados en rectificación fotográfica, sino a extremar las precauciones en su empleo. En el caso del coro alto de la capilla de San Telmo de Tui, si bien la extensión era reducida y no se planteaban problemas de ángulo de incidencia, el alto número de puntos y trazados entremezclados unos con otros desaconsejaba el empleo del método basado en estación total que se había seguido en la sacristía de Murcia o la capilla de Santa Catalina del propio Tui. Se recurrió a la toma de fotografías con un objetivo TS-E $17 \mathrm{~mm}$, pero esta vez con la columna central en posición vertical y toma oblicua (fig. 17), y al mismo tiempo se tomaron con estación total las coordenadas de una serie de puntos clave del soporte del trazado, concretamente esquinas de baldosas. Al tratarse de un objetivo de focal fija, la distorsión es muy reducida. En gabinete, en lugar de emplear un programa de rectificación fotográfica estándar para transformar las fotografías, se empleó Homograf 2002, que sigue una metodología inversa. El operador calca el trazado desde las fotografías en AutoCAD 2010, marcando también algunos puntos de coordenadas conocidas, en este caso los vértices de losas tomados con estación total. Posteriormente, se aplica Homograf 2002, que se suministra como plugin de AutoCAD; tras señalar en el dibujo los puntos de control y facilitar las coordenadas, el programa somete al dibujo a una transformación homográfica que ofrece como resultado la proyección del dibujo sobre un plano paralelo al del pavimento (Calvo, Alonso, Taín y Natividad 2013b) (fig. 8).

Los resultados alentadores obtenidos en San Telmo de Tui nos han llevado a aplicar el procedimiento en el caso de los trazados de Nogueira do Miño, realizados sobre la base de pinturas murales, como expondremos más adelante. En este caso, la extensión relativamente reducida no planteaba problemas de incidencia del rayo láser, y por el contrario, la disposición de los trazados en el plano del muro propiciaba la orientación vertical del sensor de la cámara, empleando como primera aproximación los niveles de burbuja del trípode, y corrigiendo después con el nivel electrónico de la cámara. Se intentó además que el sensor fuera paralelo al plano del muro, pero para esto no se dispone de un sistema comparable al nivel de la cámara, por lo que esta regulación se realizó de forma visual y aproximada. El procesamiento posterior da idea del éxito parcial de esta operación. En un caso se logró tal grado de paralelismo entre sensor y muro que la rectificación fue innecesaria, pero se trata de una circunstancia afortunada; en las demás fotografías fue necesario realizar pequeñas correcciones, empleando las coordenadas de puntos marcados sobre pegatinas de papel ordinario colocadas fuera de las pinturas murales o en lagunas de la capa pictórica (fig. 18, 19, 20).

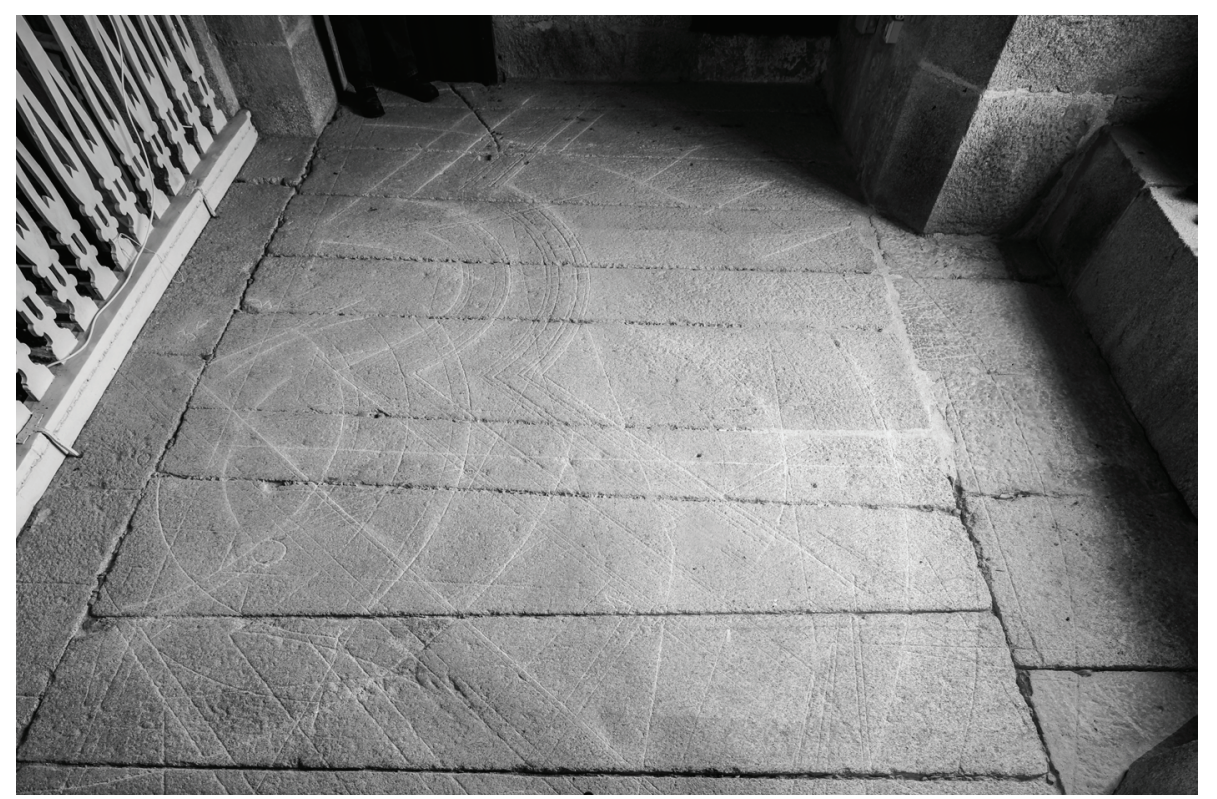

Figura 17. Fotografía oblicua de las monteas en el coro alto de la capilla de San Telmo en Tui. 

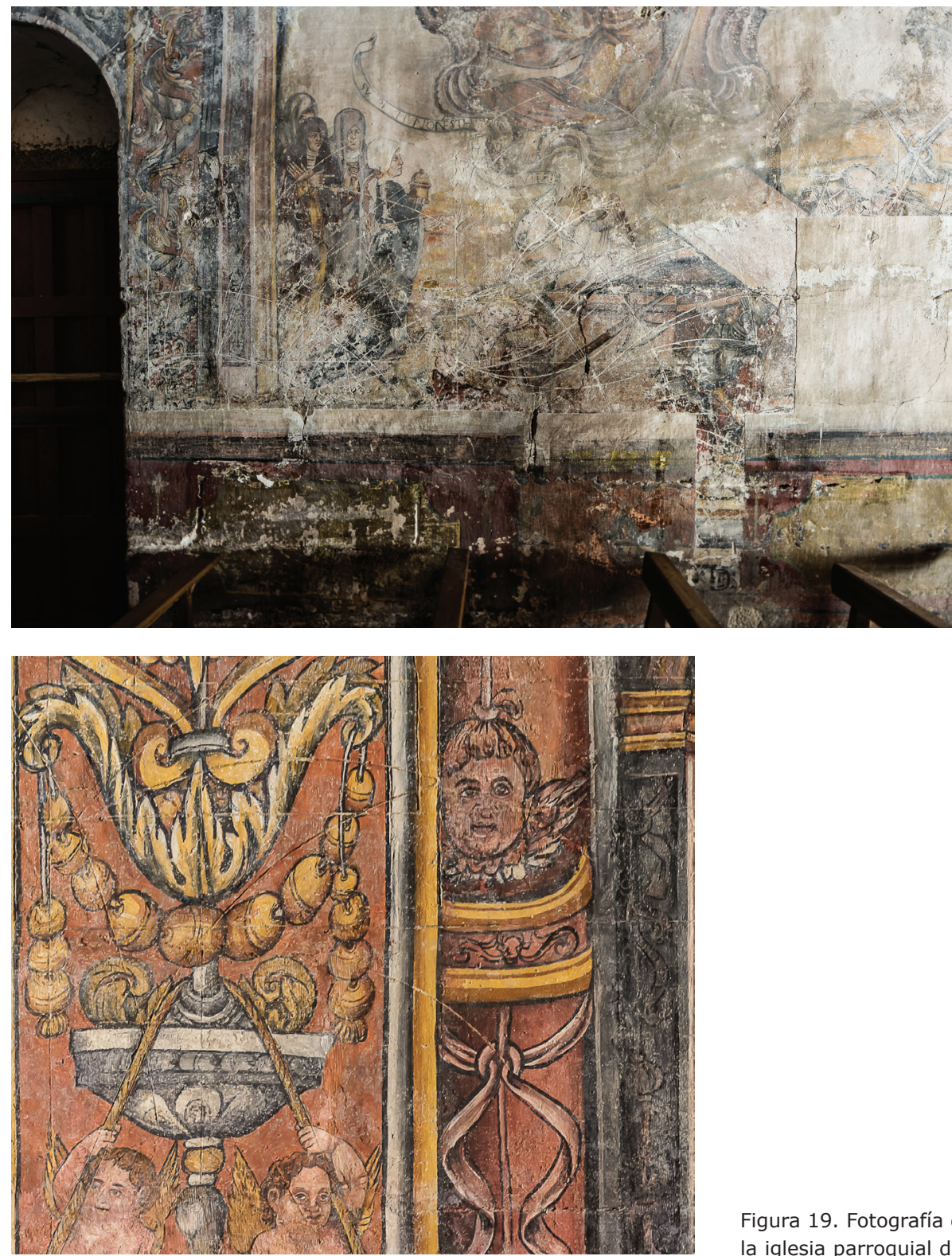

Figura 18. Fotografía de las monteas y pinturas del muro sur de la iglesia parroquial de Nogueira do Miño.
Figura 19. Fotografía de detalle de las monteas y pinturas murales de la iglesia parroquial de Nogueira do Miño.

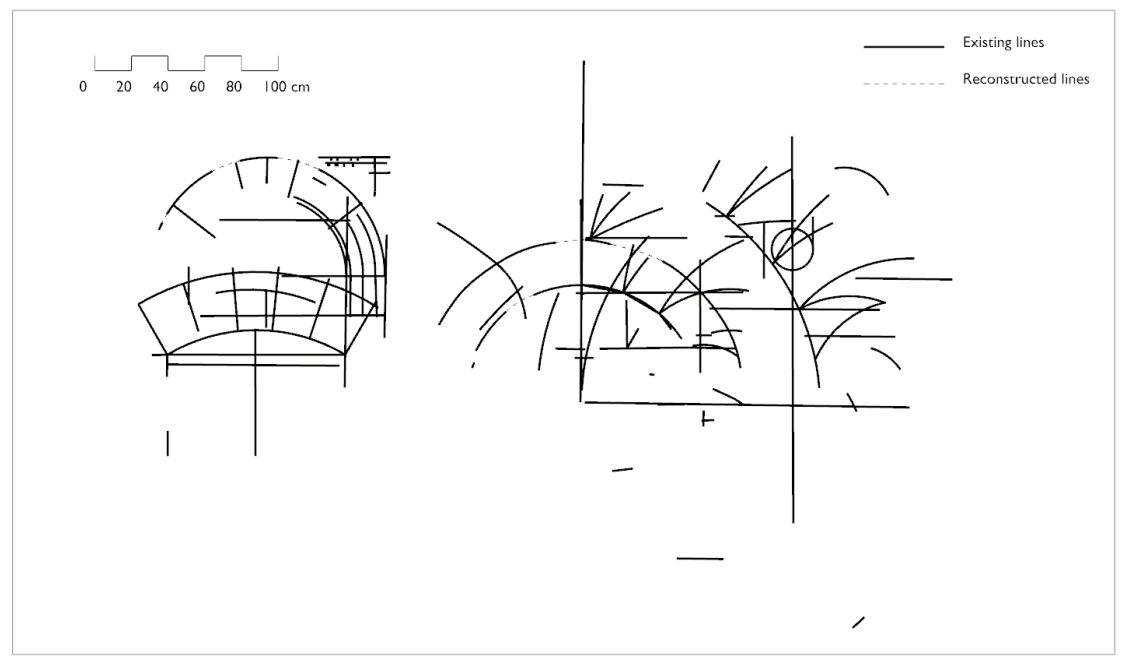

Figura 20. Levantamiento de las monteas del muro norte de la parroquial de Nogueira do Miño. 


\section{Métodos mixtos para trazados complejos}

En Agosto de 2014 apareció un extenso grupo de monteas en la iglesia conventual de Santa Clara de Santiago, inscritos en una base de granito dispuesta bajo una tarima de madera que se estaba renovando en aquel momento (Calvo y Taín 2015). El conjunto supera en complejidad a cualquier ejemplo encontrado hasta el momento y sólo es comparable en extensión a los trazados de las terrazas de la catedral de ClermontFerrand. Además, las circunstancias exigían una toma de datos relativamente rápida, pues era necesario terminar la reposición de la tarima en un plazo muy breve para interrumpir durante el menor tiempo posible el uso de la iglesia. Todo esto planteaba dificultades para el empleo de los métodos descritos en los apartados precedentes y nos ha llevado a emplear métodos ad hoc adaptados a estas circunstancias particulares; creemos que tiene interés exponerlos aquí, aunque es importante señalar que no proponemos su empleo para resolver casos más sencillos que se pueden abordar con los métodos expuestos en los dos apartados precedentes.

En primer lugar, la gran extensión del conjunto dificultaba el levantamiento mediante estación total, pues planteaba problemas de incidencia del rayo láser e incluso de simple identificación de los puntos, dada la muy escasa iluminación natural de la iglesia, obligando a realizar varios estacionamientos. En cuanto a la restitución fotográfica, se planteó en un primer momento la realización de fotografías desde un andamio móvil que permitía disponer la cámara unos $4 \mathrm{~m}$ por encima del plano del pavimento; se tomaron de esta forma una serie de fotografías por Gerardo Gil, de la empresa IKONO, cubriendo cada una un área de 2,5 $\mathrm{m}$ por $1,5 \mathrm{~m}$ aproximadamente. Si bien el conjunto ofrece una visión general de los trazados de gran interés, se comprobó que al separar la cámara de los trazados en esa distancia, se perdían algunos detalles de las monteas.

Al comprobar esta circunstancia, se tomó una segunda serie de fotografías desde el suelo, empleando las técnicas descritas al hablar de la capilla de Santa Catalina de Tui, con la columna del trípode en posición horizontal y empleando un objetivo TS-E $17 \mathrm{~mm}$ con objeto de cubrir un área relativamente amplia y evitar las patas del trípode. Esta técnica permitió cubrir la práctica totalidad de los trazados con 33 fotografías, cada una de las cuales abarcaba un área de aproximadamente $1,5 \mathrm{~m}$ por $1 \mathrm{~m}$ (fig. 21). Estas fotografías resultaron de gran utilidad para preparar un levantamiento de los trazados, como veremos, pero su rectificación sobre base topográfica hubiera resultado difícil por dos razones. En primer lugar, el escaso tiempo disponible hacía problemática la toma de coordenadas para varios puntos de cada fotografía, contando además con la dificultad de emplear varios estacionamientos dada la gran superficie cubierta, el ángulo de incidencia muy agudo que hubiera conllevado un punto de estación único y sobre todo, la escasísima iluminación de la iglesia, que hacía imposible la localización de puntos distantes a través del anteojo de la estación total.

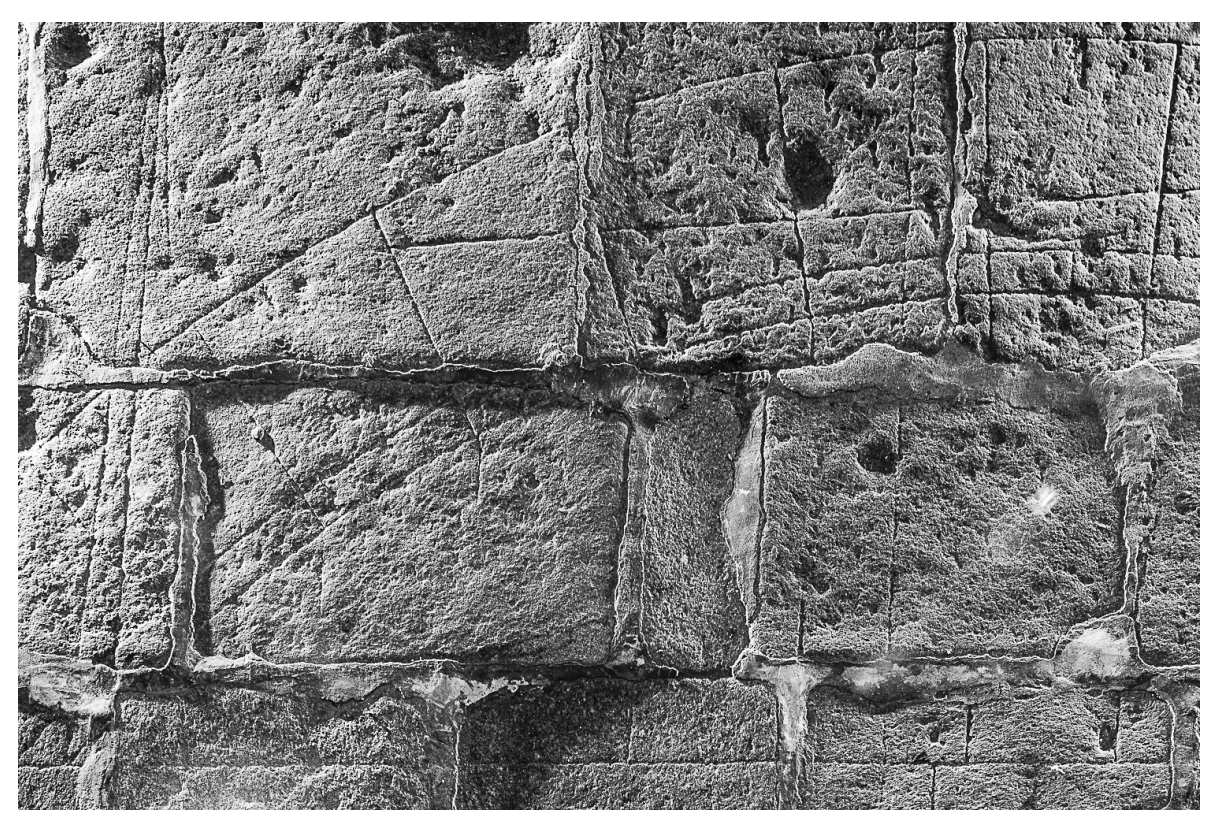

Figura 21. Fotografía de una de las monteas de la iglesia de Santa Clara de Santiago. 
Ante estas dificultades, se recurrió al levantamiento de los trazados mediante técnicas tradicionales de dibujo arqueológico, complementadas como veremos por métodos más recientes. En primer lugar, se midieron y numeraron todas las juntas del pavimento de la iglesia, tanto las continuas como las discontinuas, referidas a un levantamiento del perímetro de la iglesia obtenido por trilateración. Esto permitió disponer una rejilla, materializada en un levantamiento del solado, que se empleó como base de un primer levantamiento de los trazados por medios manuales, diferenciando las lagunas reintegradas de los trazados existentes. Este primer levantamiento permitió comprobar que, en contraste con las primeras impresiones del equipo, el estado de conservación de los trazados era bastante bueno, y que la mayor parte de las lagunas se debían a la recolocación de algunas losas, lo que permitía reintegrarlas con seguridad.

En cualquier caso, para incrementar la fiabilidad de este primer levantamiento se emplearon dos métodos con finalidades diferentes. Por una parte, se chequearon detenidamente las fotografías de la segunda serie contra el levantamiento, lo que dio lugar a la identificación de algunas discordancias entre levantamiento y fotografías; concretamente, líneas apreciables en las fotografías y no en el levantamiento y viceversa, pero también líneas recogidas en el levantamiento que a la luz de la fotografía se mostraban como arañazos en el pavimento, causadas probablemente por un objeto punzante. No se otorgó carácter decisivo ni a las fotografías ni al levantamiento inicial, pues se sospechaba que algunas líneas presentes en unas y otros podían corresponder a estos arañazos o a roturas de las losas. Por el contrario, se realizó una inspección visual detallada, para evitar errores de apreciación, en la que se resolvieron las discrepancias entre levantamiento y fotografías, obteniendo una segunda versión del levantamiento.

Ya hemos dicho que la complejidad del conjunto, unida al escaso tiempo disponible, hacía impracticable la toma de coordenadas de todos y cada uno de los puntos de los trazados, o la rectificación de las 33 fotografías de la segunda serie. Ahora bien, para descartar la posibilidad de errores significativos en el levantamiento manual, se tomaron con estación total varios puntos relevantes en cada trazado, como el inicio y final de las trazas rectilíneas, los cruces o cambios de dirección, así como varios puntos sobre los arcos y sus centros en el caso de que formasen parte de la propia traza. Esto permitió comprobar que la precisión del levantamiento era aceptable para nuestros propósitos, con errores del orden de $1 \mathrm{~cm}$ en general. Los casos de mayor discrepancia volvieron a medirse con técnica manual - trilateración - a puntos conocidos tomados con métodos topográficos, lo que permitió obtener un tercer y definitivo levantamiento (fig. 22).

\section{Desarrollos futuros}

Además de los métodos descritos en el apartado anterior para Santa Clara de Santiago, se empleó con carácter experimental un levantamiento de los trazados por fotogrametría de imágenes cruzadas con procesamiento automático de puntos, empleando el software Artec Studio, realizado por la empresa Ialma 3D, obteniendo modelos tridimensionales en formato OBJ, a partir de los cuales se han obtenido ortofotos; por último, se ha intentado calcar los trazados desde las ortofotos. En el caso del capialzado oblicuo de la portería, que presenta trazados más marcados, los resultados han sido alentadores; se

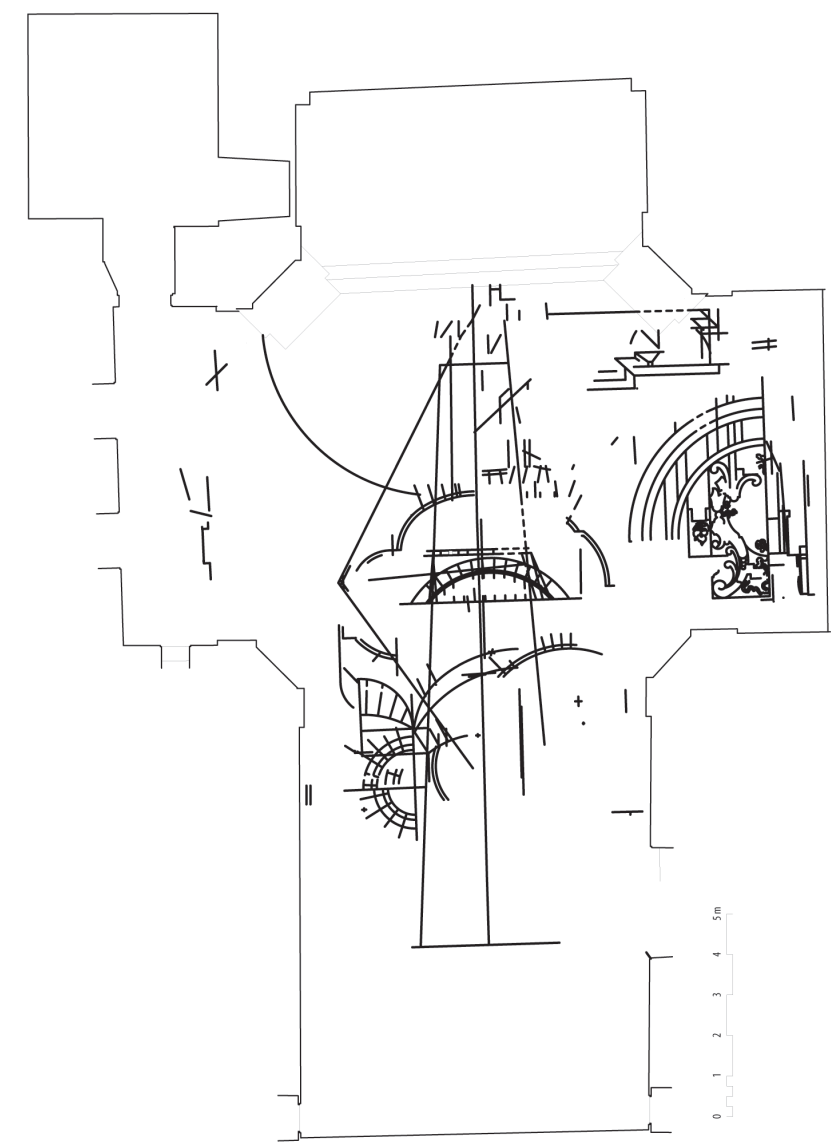

Figura 22. Levantamiento general de los trazados de cantería de la iglesia de Santa Clara de Santiago. 
han podido calcar la mayor parte de los trazados, aunque no todos. Por el contrario, en el caso de la coronación de la fachada de la portería, se aprecia claramente que muchos de los trazados no han sido recogidos en el modelo tridimensional, dada la escasa profundidad de la incisión. En cualquier caso, cabe esperar que conforme avancen las prestaciones de las cámaras y objetivos fotográficos y el diseño de los programas de fotogrametría, esta técnica podría facilitar representaciones de los trazados a tamaño natural y de las construcciones que les sirven de referente con ventajas evidentes: precisan de un tiempo de toma corto, no presentan las dificultades que hemos ido sorteando a lo largo de los apartados anteriores y están libres de las ambigüedades de interpretación que conllevan prácticamente todos los métodos anteriores, permitiendo su revisión por otros investigadores y ofreciendo un alto grado de certeza.

En la actualidad, nuestro grupo está trabajando en esta dirección empleando el software PhotoScan, que permite realizar levantamientos tanto de piezas como de trazados empleando una serie de fotografías convencionales de las que se obtiene una nube de puntos comparable en densidad a las obtenidas por los escáneres láser. En teoría, la mejor práctica pasa por disparar con trípode y emplear la sensibilidad base de la cámara, en la mayoría de los casos ISO 100, y una apertura que reduzca las aberraciones sin provocar una difracción apreciable, alrededor de f/5,6 o f/8 en función del objetivo empleado. También se recomienda en ocasiones tirar en formato RAW y convertir posteriormente las imágenes a TIFF, con objeto de evitar los artefactos de compresión habituales en el JPG. Sin embargo, la experiencia parece señalar que las fotografías tomadas sin trípode y los JPG obtenidos en calidad relativamente alta, con niveles de compresión reducidos, son aceptables en la práctica.

\section{MÉTODOS DE LEVANTAMIENTO DE CONSTRUCCIONES PARA SU COMPARACIÓN CON TRAZADOS}

No tendría sentido ofrecer aquí un panorama de los métodos de levantamiento de edificios históricos disponibles en la actualidad, entre otras cosas porque esta tarea ha sido llevada a cabo brillantemente en un número reciente de esta misma revista (Martín 2014). Nos planteamos únicamente efectuar un repaso de los métodos empleados en levantamientos efectuados con la finalidad de compararlos con trazados a tamaño natural, o en un caso concreto, a un levantamiento efectuado con anterioridad que se empleó para comparar con una montea, al comprobar que era innecesario levantar de nuevo el referente del trazado.

\section{Levantamientos por fotogrametría analítica}

La aparición en el año 1999 de un trazado de cantería en la capilla funeraria de la Gil Rodríguez de Junterón, en la catedral de Murcia, nos hizo plantearnos la necesidad de un levantamiento de las bóvedas de la capilla, llevado a cabo en 2000 por medio de fotogrametría estereoscópica a partir de imágenes de formato $6 \times 6$ tomadas con una cámara Senza Bronica SQ-Ai y un objetivo fijo Zenzanon-PS de $40 \mathrm{~mm}$, calibrado el montaje en laboratorio, en un restituidor analítico Adam MPS2, con el apoyo de un instrumento que en aquel momento era muy novedoso: una estación total dotada de distanciómetro láser, lo que le permitía prescindir del prisma y ¿medir puntos inaccesibles? La comparación del trazado, documentado mediante calcos, con el levantamiento, permitió demostrar que el trazado tenía por referente la primera estancia de la capilla, o antecapilla, y que en realidad representaba algunos elementos a tamaño natural y otros a escala 1:2 (Alonso, López y Calvo 2001; Calvo, Alonso, Rabasa y López 2005; Calvo, Molina, Alonso, López, Rabasa, Pozo y Sánchez 2010) (fig. 23, 24). Esto muestra la persistencia en una obra renacentista del principio gótico según el cual las figuras radiales se representan sin vacilaciones a escala, pues se dominan las técnicas para replantearlas a escala natural. Por lo demás, la fotogrametría analítica se reveló como un instrumento eficaz para recoger la riquísima decoración de la recapilla (fig. 25), pero la evolución posterior de las técnicas de levantamiento ha hecho que nuestro equipo no haya continuado con el uso de este método.

\section{Levantamientos con estación total}

Los resultados satisfactorios del levantamiento de la capilla de Junterón llevaron a nuestro equipo a abordar otros levantamientos detallados de piezas de cantería en la catedral de Murcia, sin plantearnos la posibilidad de compararlos con trazados de otras piezas, que no habían aparecido en aquel momento. Entre otras piezas que no son relevantes para este artículo, se levantó en 2002 la bóveda de la sacristía catedralicia, tomando con estación la totalidad de los vértices de sus dovelas, estrías y gallones, 


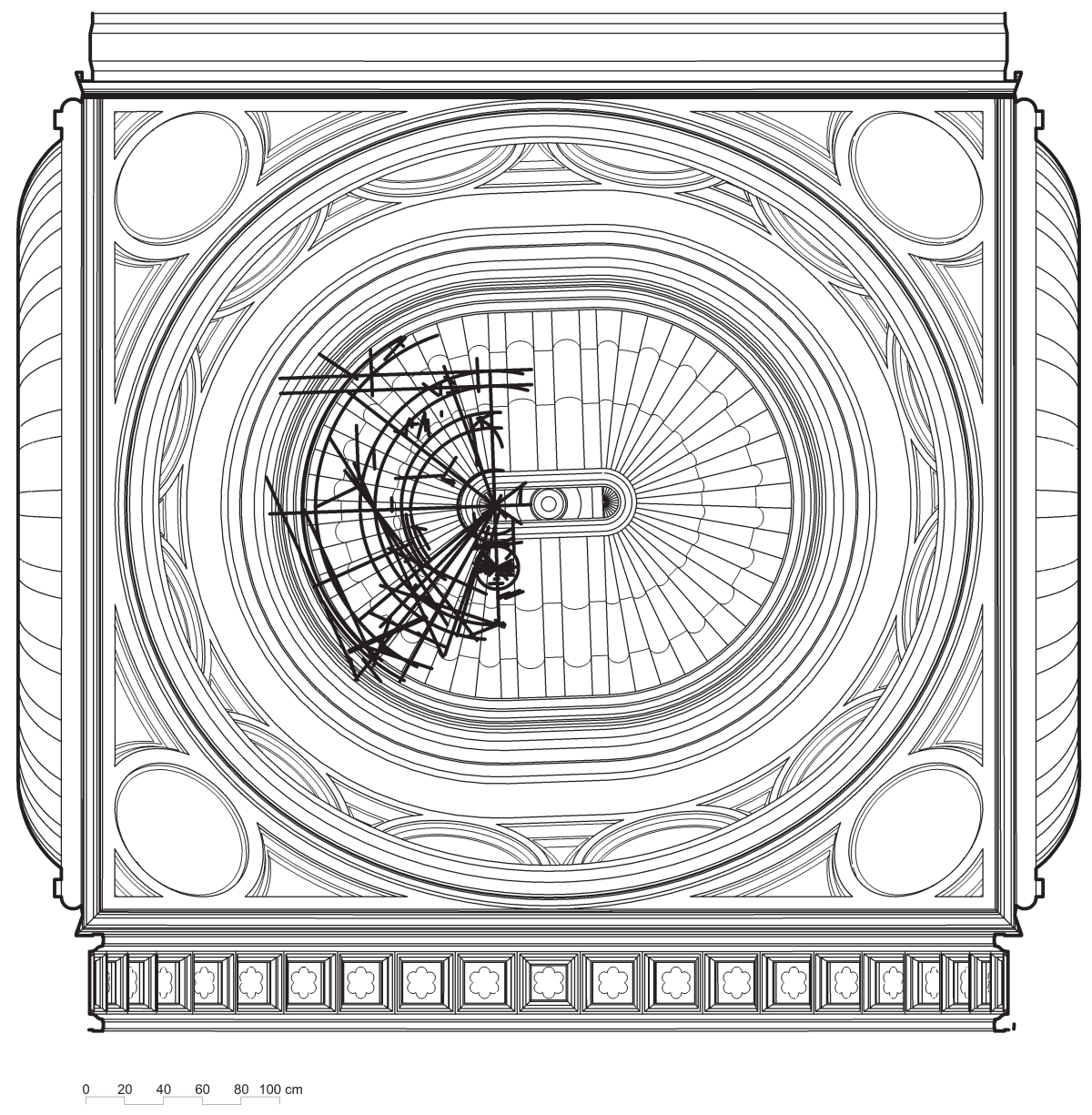

Figura 23. Trazado de la capilla de Junterón de la catedral de Murcia, superpuesto a las bóvedas de la antecapilla a escala $1: 1$. con un total de más de 5000 puntos. Al aparecer en 2009 el trazado de la bóveda, se comprobó que el levantamiento de 2002 era fiable y se comprobó con el levantamiento preciso de la bóveda que hemos descrito más arriba.

Con posterioridad, nuestro equipo ha realizado levantamientos con estación total en otras localizaciones, como la sacristía de la catedral de Tui o la capilla de San Telmo de esta ciudad. Si bien la precisión de estos levantamientos está fuera de duda y es más que suficiente para nuestros fines, su utilidad queda limitada por los largos tiempos de toma que exigen los levantamientos detallados, dovela a dovela, que son necesarios para comparar las piezas con los trazados efectuados para resolver problemas estereotómicos. A esto se une además, las dificultades que plantea el levantamiento de bóvedas nervadas, por la situación de sombra en la que quedan muchas veces los puntos de encuentro de nervios y plementería. Todo esto nos ha llevado, en casos como el de la capilla de San Telmo de Tui o la parroquial de Nogueira do Miño, a no intentar un verdadero levantamiento de estos edificios, que no era necesario para nuestros propósitos, sino más modestamente, tomar los puntos clave que permiten definir luces, flechas o trazados de arcos para compararlos con los levantamientos de los trazados.

\section{Levantamiento por fotogrametría de imágenes cruzadas}

En teoría, la fotogrametría de imágenes cruzadas se presta bien a los estudios estereotómicos, pues lo que se pretende es conocer la geometría de unas dovelas definidas por sus vértices, que son puntos bien definidos y fácilmente obtenibles por esta técnica, sin necesidad de recurrir a la detección automática de puntos, que facilita puntos indiscriminados. Sin embargo, a la hora de comparar con trazados sólo la hemos empleado en un caso singular. Por motivos que no vienen al caso, el tiempo disponible para efectuar un levantamiento del interior de la iglesia de Santa Columba de Carnota era limitadísimo. Por esta razón, un operador tomó alrededor de veinte fotografías de las bóvedas de horno de los 


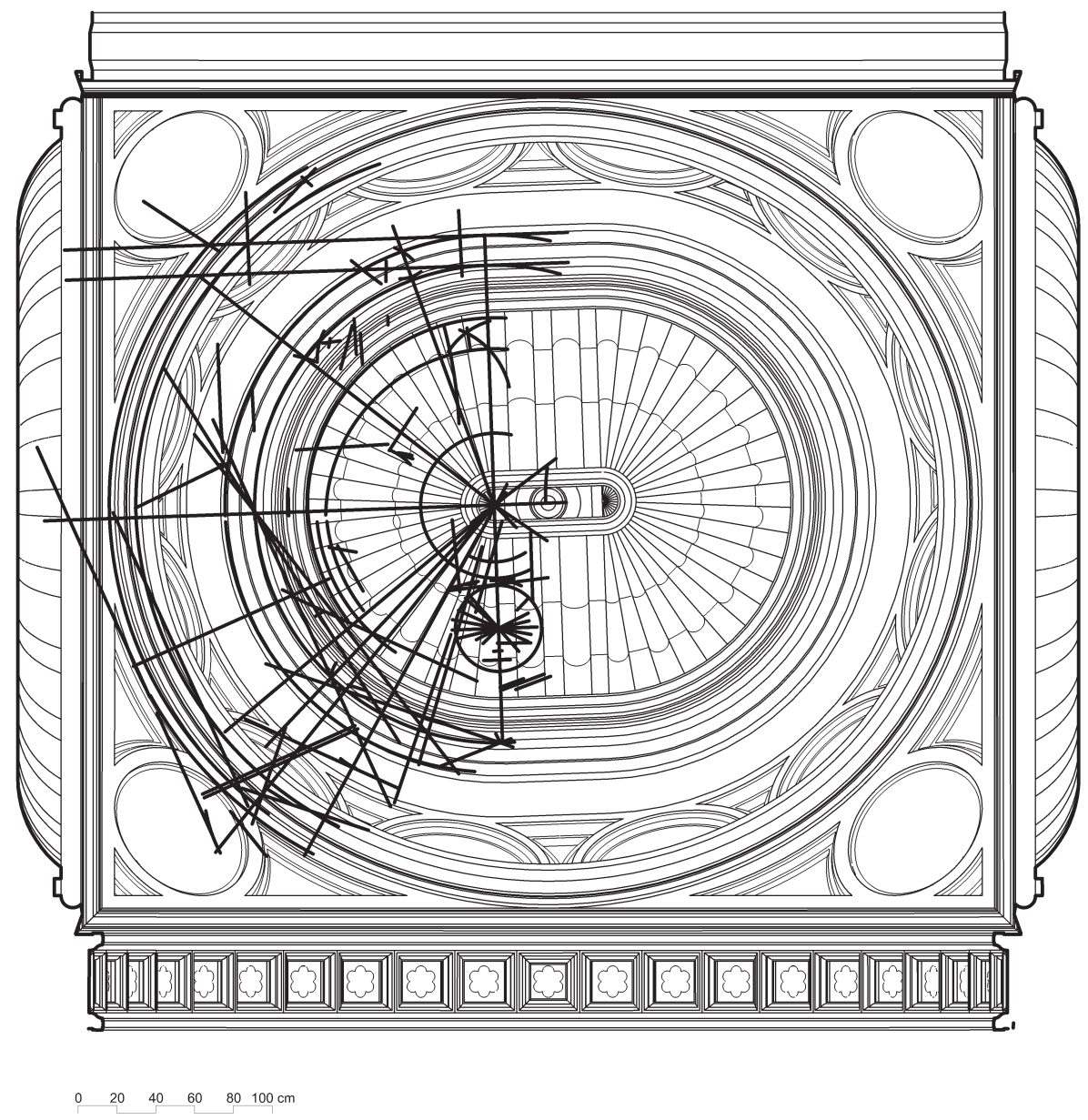

Figura 24. Trazado de la capilla de Junterón de la catedral de Murcia, superpuesto a las bóvedas de la antecapilla a escala $1: 2$. pies, a razón de diez por bóveda, en un tiempo de diez minutos aproximadamente, por supuesto sin emplear trípode. Posteriormente se procesaron las fotografías en gabinete, empleando Photomodeler 6.0, lo que permitió construir un modelo tridimensional alámbrico de ambas

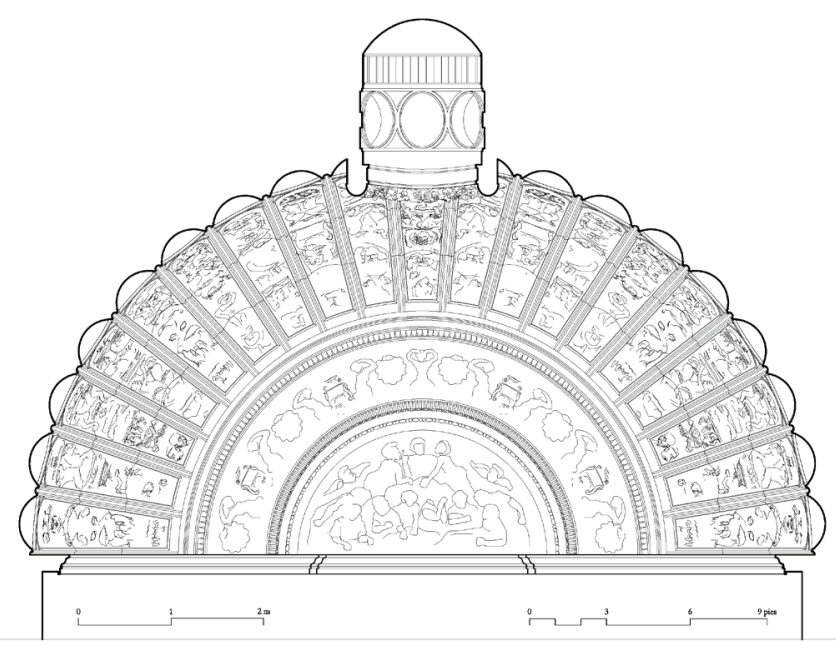

Figura 25. Sección longitudinal de la bóveda de la recapilla de Junterón de la catedral de Murcia. bóvedas, a partir del cual se obtuvieron plantas y alzados que se compararon con los trazados (fig. 3). Tampoco presentó dificultades la obtención de un modelo de superficies del intradós de las bóvedas, pero conviene dejar claro que se empleó a efectos de presentación en un congreso (Taín y Natividad 2011) y no para compararlo con los trazados. Como es obvio, la naturaleza lineal de las monteas aconseja compararlas con una representación igualmente lineal de las piezas construidas, dejando las imágenes coloreadas para presentaciones más o menos espectaculares.

\section{Levantamiento por escáner láser 3D}

Como hemos dicho, en el caso de los trazados de Santa Clara de Santiago resultó evidente desde el principio su relación con el edificio de la portería del convento, lo que aconsejaba disponer de una representación fiable para su comparación con las monteas. Si bien en un primer momento se barajó la posibilidad de emplear fotogrametría de imágenes cruzadas, pronto se comprendió que dada la rica ornamentación de la fachada el método más fia- 
ble pasaba por la utilización de un escáner laser 3D. El trabajo fue contratado por el Consorcio de Santiago con la empresa Compass, S. L., que lo realizó empleando un escáner Faro Focus. En contra de algunos relatos acríticos sobre este medio de levantamiento que se han puesto en circulación en los últimos años, la toma no estuvo exenta de dificultades. Debido a que el espacio disponible frente a la fachada era relativamente escaso, en los primeros intentos de escaneado, desde la calle y desde la escalera de acceso al convento, la parte superior quedaba sin definición suficiente, siendo impracticable la definición manual de aristas a partir de la nube de puntos, y mucho menos la determinación automática de aristas que proponen las casas comerciales. En cualquier caso, se obtuvo una ortofoto utilizable, si bien presenta artefactos visibles en las cornisas y en algunos elementos de la parte superior (fig. 26). Para subsanar esta dificultad se realizaron tomas adicionales de fotogrametría de imágenes cruzadas desde una ventana dispuesta en un muro perpendicular a la fachada, lo que permitió preparar un

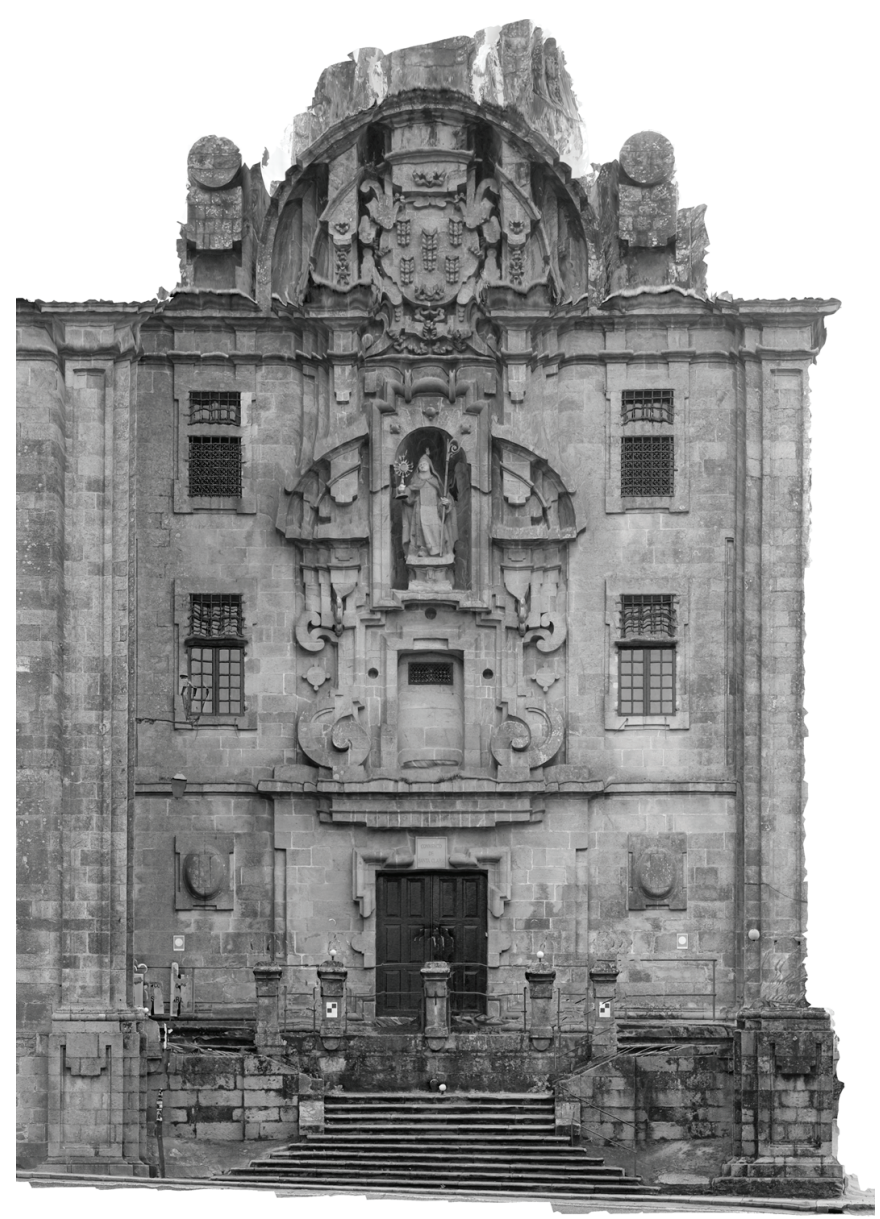

Figura 26. Ortofoto de la fachada de la portería de Santa Clara de Santiago. Compass, S. L. alzado a línea calcando digitalmente desde la ortofoto, complementado con tomas de puntos mediante estación total en las zonas mal definidas o afectadas por los artefactos, que afortunadamente eran en general las menos decoradas. Al mismo tiempo se realizó un escaneo del vestíbulo de la portería; el carácter interior de este espacio y la posibilidad de estacionar en cualquier punto de la planta ha hecho que este trabajo no presente dificultades, obteniendo entre otras cosas plantas y alzados del capialzado. Estas plantas y alzados a línea han permitido la comparación con el levantamiento del trazado al que hemos hecho referencia más arriba, lo que ha permitido determinar entre otras cosas, la precisión de la ejecución del capialzado, el alargamiento de la coronación, o la existencia de diversos trazados de tanteo para el nicho de Santa Clara.

\section{OPORTUNIDADES DE INVESTIGACIÓN Y RETOS DE CONSERVACIÓN}

Hemos visto en los apartados anteriores que los trazados de arquitectura a tamaño natural pueden ofrecer materiales de gran interés para la historia de la arquitectura y la construcción, siempre en combinación con otras fuentes tradicionales. Nos informan de la evolución de la ejecución de las construcciones, de las modificaciones de diseño introducidas antes del comienzo de la ejecución efectiva o sobre la marcha, de la personalidad de los directores de las obras, e incluso de los métodos de talla empleados, e indirectamente de los conocimientos geométricos de arquitectos y canteros.

Es importante recalcar que las monteas ofrecen todo su potencial en combinación con otras fuentes: por ejemplo, rara vez las monteas permiten datar una construcción, pues la evolución de las técnicas de trazado es en general relativamente lenta; al contrario, son habitualmente las construcciones las que hacen posible fechar los trazados. En ocasiones, es la documentación de archivo la que permite datar las monteas, pero en otros casos la arqueología de la arquitectura puede confirmar o precisar estas dataciones documentales. En ese sentido, es esencial enmarcar la montea en el contexto de la unidad estratigráfica que le sirve de soporte, ya sea un pavimento o un revestimiento mural. En otros casos, la montea en sí misma puede ser considerada unidad estratigráfica, pues es frecuente que la montea se realice décadas o siglos después de la ejecución del soporte, y en ocasiones se sitúa entre 
el soporte y una unidad estratigráfica posterior, como en el caso de Nogueira do Miño, donde queda entre las pinturas murales del siglo XVI y los recubrimientos de cal del siglo XVIII. Por el contrario, en la sacristía de Murcia el lapso entre unas unidades y otras es mucho más corto: el trazado de la bóveda se dispone sobre un muro levantado a partir de Octubre de 1521 y bajo una singular "unidad estratigráfica": la sillería comenzada a ejecutar por Jacopo Torni antes de su fallecimiento en Enero de 1526.

Ahora bien, para todo esto es imprescindible, obviamente, una conservación adecuada de las monteas; de lo contrario se perderán para la investigación actual y para las generaciones futuras. En muchos casos, los trazados se han conservado adecuadamente simplemente porque estaban ocultos, como en la sacristía de Murcia o en la iglesia de Santa Clara. En casos como estos, la reintegración de la protección, renovando o recolocando el solado o volviendo a montar en su lugar la cajonería después de su tratamiento contra los xilófagos es la mejor medida de conservación, a condición, claro está, de proceder a una documentación rigurosa antes de recolocar la protección. Una solución similar se ha adoptado en la sala de trazas de la catedral de Sevilla, donde después de su estudio se ha colocado sobre la frágil capa de yeso una tarima protectora de madera que ha permitido la utilización del espacio como estudio o taller destinado precisamente a la preparación de proyectos de conservación de la catedral (Pinto y Jiménez 1993).

En otros casos, como las monteas de Carnota, o las halladas en el Palacio Capitular compostelano o en las proximidades de la trompa de las Platerías de la misma ciudad (Taín 2003b, 2006; Taín y Natividad 2011), han estado dispuestas al exterior durante varios siglos, sin graves daños aparentes. Sin embargo, los problemas de erosión debidas a cambios de temperatura, sales por contaminación unidas a cambio de humedad, azote de lluvia y viento con partículas de polvo que pueden actuar como proyectiles, acción del hombre como pintadas u otros, aconsejan realizar un estudio específico, incluyendo un ensayo acelerado de sometimiento a ciclos climáticos del granito en el que están incisas, para asegurar su conservación a largo plazo.

Un caso excepcional es el de las monteas de Nogueira do Miño, realizadas en el siglo XVIII sobre la base de unas pinturas murales del siglo XV que en aquel momento se consideraban amortizables y se cubrieron con una capa de cal. Los trazados, realizados con puntero, atraviesan las capas de cal añadidas en el siglo XVIII y llegan hasta la capa pictórica. Esta circunstancia permite conservar simultáneamente los trazados y las pinturas, pero plantea un problema: ¿deben reintegrarse las monteas como si fueran lagunas de las pinturas? Dicho en otros términos, ¿debe privilegiarse la lectura de las pinturas o la de los trazados? Al final se optó por rellenar los trazados con acuarela, y el efecto es similar al regattino: el trazado se percibe a corta distancia, e incluso sobre fotografías de alta definición realizadas con trípode, pero no perturba la lectura de la pintura (Cagigal 2014).

Paradójicamente, las monteas que han sufrido mayores agresiones en los últimos años han sido las existentes en lugares que posteriormente se han utilizado como museo. Conservadas durante siglos en espacios más o menos recónditos de catedrales o conventos, al destinarse algunas estancias a museo han sufrido las agresiones de un uso más intenso e, incomprensiblemente, de una limpieza con productos inapropiados. Así, las monteas antropomórficas de la catedral de Santiago, unas piezas únicas, perfectamente reconocibles en 2003, han desaparecido desde entonces, debido al pulido mecánico del pavimento de piedra. Otro tanto parece estar ocurriendo en el trazado bajo la escalera triple de Santo Domingo de Bonaval, que ha perdido definición desde que fuera localizada en 2005. Pero lo más incomprensible es lo ocurrido con una serie de monteas en el museo de la catedral de Santiago, en dos estancias contiguas que pueden haber desempeñado el papel de sala de trazas, destinadas a la exhibición de piezas por el museo catedralicio. Con posterioridad a la publicación de las monteas en 2003, se ha dispuesto sobre los trazados peanas y vitrinas para la exposición de piezas de las colecciones de arte sacro y bancos para el descanso del público, lo que impide la visualización del conjunto y nuevos estudios del mismo.

Estos episodios desafortunados muestran que la mejor medida de conservación preventiva es precisamente dar a conocer la existencia de estos trazados, mostrando su utilidad como fuentes de la historia de la arquitectura, y no sólo a un público de especialistas, sino a una audiencia más general, como ha hecho el Consorcio de Santiago al celebrar dos jornadas de puertas abiertas en el convento de Santa Clara para mostrar a los compostelanos este conjunto único de fuentes de la cultura material. 


\section{AGRADECIMIENTOS}

Varios de los viajes necesarios para llevar a cabo los levantamientos descritos en el artículo fueron financiados por el Proyecto de Investigación "Documentación y análisis de los trazados de cantería de la catedral de Murcia" de la Fundación Séneca - Agencia Regional de Ciencia y Tecnología de la Región de Murcia. El estudio de la bóveda nervada de la catedral de Tui se inscribe en el Proyecto "La construcción de bóvedas tardogóticas españolas en el contexto europeo. Innovación y transferencia de conocimiento" (BIA2013-46896-P) del Programa de Excelencia del Plan Nacional de $\mathrm{I}+\mathrm{D}+\mathrm{i}$, financiado por el Ministerio de Economía y Competitividad.

Deseamos agradecer las facilidades para desarrollar nuestro trabajo ofrecidas por el deán y cabildo de la catedral de Murcia, el cabildo de la catedral de Tui, la cofradía de San Pedro González Telmo, la familia Vila, el párroco de Nogueira do Miño, la empresa CREA-Restauración, el Consorcio de Santiago, las empresas Construcciones Torres Cambre, S. L. y Compass, S. L. y la comunidad de monjas clarisas de Santa Clara de Santiago.

\section{BIBLIOGRAFÍA}

Alberti, L. B. 1966: L'architettura (De re aedificatoria). Orlandi, G., ed. Il Polifilo, Milano.

Alonso Rodríguez, M. Á., López Mozo, A. y Calvo López, J. 2001: “Levantamiento de las bóvedas de la capilla de Junterón de la catedral de Murcia", en III Jornadas de Fotogrametría Arquitectónica. Universidad de Valladolid, Valladolid.

Alonso Rodríguez, M. Á.; Calvo López, J. y Rabasa Díaz, E. 2009: “Sobre la configuración constructiva del crucero de la catedral de Segovia”. En S. Huerta, R. Marín, R. Soler y A. Zaragozá (eds.), Actas del Sexto Congreso Nacional de Historia de la Construcción, p. 53-62. Instituto Juan de Herrera, Madrid.

Barnes, C. F. J. 1972: "The gothic architectural engravings in the cathedral of Soissons", Speculum, vol. 47, n 1, p. 60-64.

Bessac, J.-C. 1985: “Tracés et épures gravés dans l'ancienne cathédrale Saint-Just de Narbonne (Aude)", en Actes du Colloque international de glyptographie de Cambrai, pp. 35-55. Centre International de Recherches Glyptographiques, Braine-le-Château.

Bosse, A. 1643: La practique du traict a preunes de M. Desargues ... pour la coupe des pierres en l'Architecture ... Pierre des Hayes, Paris.

Branner, R. 1960: "Villard de Honnecourt, Archimedes and Chartres", Journal of the Society of Architectural Historians, vol. 19, $\mathrm{n}^{\circ}$ 3, pp. 91-96.

Branner, R. 1987: “An Unknown Gothic (?) Drawing from Saint-Quentin”, Gesta, vol. 26, n 2, pp. 151-152.

Bucher, F. 1977: "A rediscovered tracing by Villard de Honnecourt", Art Bulletin, vol. 59, n 3, pp. 315-318

Cagigal, M. A. 2014: Informe sobre las pinturas murales de Nogueira do Miño. Archivos de la Xunta de Galicia.

Cabezas, L. (ed.) 2011: Dibujo y construcción de la realidad. Madrid: Cátedra.
Calvo López, J., Alonso Rodríguez, M. Á., Rabasa Díaz, E. y López Mozo, A. 2005: Cantería renacentista en la Catedral de Murcia. Murcia, Colegio Oficial de Arquitectos de Murcia.

Calvo López, J., Molina Gaitán, J. C., Alonso Rodríguez, M. Á., López Mozo, A., Rabasa Díaz, E., Pozo Martínez, I. y Sánchez Pravia, J. A. 2010: "El uso de monteas en los talleres catedralicios: el caso murciano", SEMATA, Ciencias Sociais e Humanidades, vol. 22, pp. 519-536.

Calvo López, J. y Ros Sempere, M. 2011: "Los instrumentos de los canteros en la transición del gótico al Renacimiento", en Alonso, B. ed., La arquitectura tardogótica castellana entre Europa y América, p. 427-433. Sílex, Madrid.

Calvo López, J., Molina Gaitán, J. C., Natividad Vivó, P., Alonso Rodríguez, M. Á., Rabasa Díaz, E., López Mozo, A., Taín Guzmán, M. y Sánchez Pravia, J. A. 2013a: "The Tracing for the Sail Vault at the Murcia Cathedral Vestry: Surveying a 16th-Century Full-Scale Working Drawing”, International Journal of Architectural Heritage, vol. 7, $\mathrm{n}^{\circ} 3$, p. 275-302.

Calvo López, J., Alonso Rodríguez, M. A., Taín Guzmán, M. y Natividad Vivó, P. 2013b: "La construcción en cantería en la Galicia barroca. Las monteas del coro alto de la capilla de San Telmo de Tui", Informes de la Construcción, vol. 65, $\mathrm{n}^{\circ}$ 2, p. 127-140.

Calvo López, J. y Taín Guzmán, M. 2015: Informe histórico sobre las monteas del convento de Santa Clara de Santiago. Archivo del Consorcio de Santiago.

Cheréau, J. c. 1567-1574: Livre d'Architecture, Gdansk, Biblioteca Municipal, Ms. 2280.

Choisy, A. 1899: Histoire de l'Architecture. Gauthier-Villars, Paris.

Claval, F. 1990: Les secrets d'une cathédrale et de ses bâtisseurs : tracés et épures du XIIIe siècle à la Cathédrale de Clermont-Ferrand. Les Amis de la Cathédrale et de l'Art Sacré, Clermont-Ferrand.

Curabelle, J. 1644: Examen des oeuvres du Sieur Desargues. M. \& I. Henault - F. L'Anglois dit Chartres, Paris.

Della Francesca, Piero 1942: De prospectiva pingendi. Nicco-Fasola, G., ed. Sansoni, Firenze

De L'Orme, P. 1567: Le premier tome de l'Architecture, Federic Morel, Paris

De la Rue, J. B. 1728: Traité de la coupe des pierres où par méthode facile et abrégée l'on peut aisément se perfectionner en cette science. Imprimerie Royale, Paris.

Derand, F., 1643: L'Architecture des voûtes ou l'art des traits et coupe des voûtes ... Sébastien Cramoisy, Paris.

Desargues, G. 1640: Brouillon project d'exemple d'une manière universelle du S.G.D.L. touchant la practique du trait a preunes pour la coupe des pierres en l'architecture ..., Melchoir Tavernier, Paris

Di Teodoro, F. P. 2003: Raffaello, Baldassar Castiglione e la Lettera a Leone $X .2$ ed. Minerva, Bologna.

Dürer, A. 1525: Underweysung der messung mit dem zirkel und richtscheyt .. Nuremberg, s. $n$.

Fergusson, P. J. 1979: "Notes on two engraved cistercian drawings", Speculum, vol. 54, pp. 1-17.

Fernández Sarela, F. 2014: Algunos cortes de Arquitectura. Santiago de Compostela, Archivo Provincial Franciscano de Santiago. Cortés López, M. E., ed. Santiago de Compostela, Xunta de Galicia.

Frankl, P. 1953: "The 'Crazy' Vaults of Lincoln Cathedral”, Art Bulletin, vol. $35, n^{\circ} 2$, pp. 95-107.

Freire Tellado, M. J. 1998: "Los trazados de montea de factura renacentista del edificio de los escolapios de Monforte de Lemos (Lugo)", en F. Bores, J. Fernández, S. Huerta y E. Rabasa, eds., Actas del Segundo Congreso Nacional de Historia de la Construcción. Instituto Juan de Herrera, Madrid.

Frézier, A. F. 1737-1739: La théorie et la pratique de la coupe des pierres et des bois pour la construction des voutes et autres parties des bâtiments civils et militaires ou traité de stéréotomie a l'usage de l'architecture. Jean Daniel Doulsseker-L. H. Guerin, Strasbourg-Paris

Gil de Hontañón, R. 1991: Manuscrito. Incluido en García, S., Compendio de arquitectura y simetría de los templos. Bonet Correa, A. y Rodicio Rodríguez, C., eds. Colegio de Arquitectos, Valladolid. 
Gelabert, J. 2011. El manuscrito de cantería de Joseph Gelabert. Rabasa Díaz, Enrique, ed. Palma de Mallorca - Madrid: Col.legi Oficial d'Arquitectes de les Illes Balears - Fundación Juanelo Turriano.

Guardia, A. d. c. 1600. Rasguños de arquitectura y cantería. Madrid, Biblioteca Nacional de España, ER/4196.

Guarini, G. 1737: Architettura Civile del padre D. Guarino Guarini chierico regolare opera postuma dedicata a sua sacra reale maesta. Gianfrancesco Mariesse, Torino.

Harvey, J. 1968: "The tracing floor in York Minster", Annual Report of the Friends of York Minster, $\mathrm{n}^{\circ}$ 40, pp. 1-8.

Haselberger, L. 1983: "Die Bauzeichnungen des Apollontempels von Dydima", Architectura, vol. 13, n 1, pp. 13-26.

Haselberger, L. 1994: "The Hadrianic Pantheon - a Working Drawing Discovered", American Journal of Archaeology, vol. 98, n 2, p. 327.

Hastings, M. 1955: St Stephen's Chapel and its place in the development of perpendicular style in England, Cambridge University Press, Cambridge.

Holton, A. 2006: "The Working Space of the Medieval Master Mason: the Tracing Houses of York Minster and Wells Cathedral", en Dunkeld, M ed., Proceedings of the Second International Congress on Construction History, Construction History Society, Cambridge

Jousse, M. 1642: Le secret d'architecture découvrant fidélement les traits géométriques, couppes et dérobements nécessaires dans les bastimens. Georges Griveau, La Flèche.

López Mozo, A., Senent Domínguez, R., Alonso Rodríguez, M. A., Calvo López, J. y Natividad Vivó, P. 2015: “Asymmetrical vaults in late European Gothic: Basel and Bebenhausen as case studies", en 5th International Congress on Construction History, vol. 2. Construction History Society of America, Chicago.

López Vílchez, I. 2011: "Representación técnica", en Dibujo y construcción de la realidad, Madrid: Cátedra.

Lotz, W. 1956: "Das Raumbild in der architekturzeichnung der italianischen Renaissance", Mitteilungen des Kunsthistoriches Instituts in Florenz, $\mathrm{n}^{\mathrm{o}}$ 6, p. 193-226. (Tr. 1977 in Studies on Italian Rennaissance Architecture, pp. 1-65. MIT, Cambridge, Mass.).

Manuscrito anónimo de cantería c. 1545. Madrid, Biblioteca Nacional de España, Ms. 12.686.

Manuscrito anónimo de cantería c. 1650. Madrid, Biblioteca Nacional de España, Ms. 12.744.

Martínez de Aranda, G. 1986: Cerramientos y trazas de montea. Bonet Correa A. y Mañas, J. Servicio Histórico del Ejército-CEHOPU, Madrid.

Martín Talaverano, R. 2014: "Documentación gráfica de edificios históricos: principios, aplicaciones y perspectivas". Arqueología de la Arquitectura, $\mathrm{n}^{\circ}$ 11, doi: http://dx.doi.org/10.3989/arq.arqt.2014.014

Milliet de Challes, C. F. 1674: Cursus seu mundus mathematicus. Officina Anissoniana, Lugduni.

Monge, G. 1798: Géométrie descriptive, leçons données aux Écoles normales, l'an 3 de la République ..., Baudouin, Paris.

Pérez de los Ríos, C. y Rabasa Díaz, E. 2014 "Stretched templates in Gothic tas-de-charge construction", en Proceedings of the First Conference of the Construction History Society, Construction History Society, Cambridge.

Pinto Puerto, F. y Jiménez Martín, A. 1993: "Monteas en la Catedral de Sevilla”, Revista de Expresión Gráfica Arquitectónica (EGA), nº 1, pp. 79-84.

Pita Galán, P. 2014: “Arquitectos, maestros de obras, canteros y carpinteros: los frailes legos en la fábrica del convento de San Francisco de Santiago", Ad Limina. Revista de Investigación del Camino de Santiago y las Peregrinaciones, $\mathrm{n}^{\mathrm{o}} 5$, pp. 95-112.

Portor y Castro, J. 1708: Cuaderno de arquitectura. Madrid, Biblioteca Nacional de España, Ms. 9114.

Rabasa Díaz, E. 1996: “Técnicas góticas y renacentistas en el trazado y la talla de las bóvedas de crucería españolas del siglo XVI”, en Casas Gómez, A. ed., Actas del Primer Congreso Nacional de Historia de la Construcción, pp. 423-434. Instituto Juan de Herrera, Madrid.

Rabasa Díaz, E. 2000: Forma y construcción en piedra. De la cantería medieval a la estereotomía del siglo XIX, Akal, Madrid.

Rojas, Cristóbal de. 1598.: Teórica y práctica de fortificación, conforme a las medidas de estos tiempos ... Luis Sánchez, Madrid.
Roriczer, M. 1486: Büchlein von der fialen Gerechtigkeit. s. n., Regensburg. Ruiz, H. 1998: Libro de Arquitectura. Jiménez, A., ed. Sevillana de Electricidad, Sevilla.

Ruiz de la Rosa, J. A. 1987: Traza y simetría de la arquitectura en la Antigüedad y el Medievo. Universidad de Sevilla, Sevilla.

Ruiz de la Rosa, J. A. 1996: "Giralda - Catedral gótica", en Quatro edificios sevillanos, pp. 17-71. Colegio de Arquitectos, Sevilla.

Ruiz de la Rosa, J. A. y Rodríguez Estévez, J, C. 2002: “ 'Capilla redonda en vuelta redonda' (sic): Aplicación de una propuesta teórica renacentista para la catedral de Sevilla", en IX Congreso Internacional Expresión Gráfica Arquitectónica. Re-visión: Enfoques en docencia e investigación, pp. 509516. Universidad de A Coruña, La Coruña.

Sakarovitch, J. 1992: "La coupe des pierres et la géometrie descriptive", en Dhombres, J., ed., L'Ecole Normale de l'an III Leçons de Mathématiques, Laplace-Lagrange-Monge. Paris, Dunod.

Sakarovitch, J. 1995: "The Teaching of Stereotomy in Engineering schools in France in the XVIIIth and XIX centuries: an Application of Geometry, an 'Applied Geometry', or a Construction Technique?', en Radelet-de Grave, P. y Benvenuto, E., ed., Entre mécanique et architecture, pp. 204-2018. Birkhäuser, Basel-Boston-Berlin.

Sakarovitch, J. 1997: Epures d'architecture. Birkhäuser, Basel-BostonBerlin.

San Nicolás, Fray Laurencio de. 1639: Arte y uso de Arquitectura, s. n., s. 1.

Sanzio, R. y Castiglione, B. 2003: Lettera a Leone X, en Raffaello, Baldassar Castiglione e la Lettera a Leone X. Di Teodoro, F. P., Minerva, Bologna, $2^{\text {a }}$ ed.

Sebastiá Esteve, M. A. 2011: "Trazas del siglo XVIII encontradas en la iglesia parroquial de San Juan Bautista de Cabanes (Castellón)", en Huerta, S., ed., Actas del Séptimo Congreso Nacional de Historia de la Construcción, p. 1311-1320. Instituto Juan de Herrera, Madrid.

Shelby, Lon R. 1977: "Introduction", en Gothic Design Technics: The fifteenth-century design booklets of Mathes Roriczer and Hans Schmuttermayer. Carbondale: Southern Illinois University Press.

Taín Guzmán, M. 2003a: "Las monteas de la Catedral de Santiago de Compostela: de la arquitectura a la escultura", en Correspondencia e Integración de las Artes. XIV Congreso Nacional de Historia del Arte, pp. 509-522. Comité Español de Historia del Arte, Málaga.

Taín Guzmán, M. 2003b: "Las monteas en Galicia: propuesta de una tipología", Goya, no 297, pp. 339-355.

Taín Guzmán, M. 2003c: "The drawings on stone in Galicia: Types, uses and meanings", en Huerta Fernández, S., ed., Proceedings of the First International Congress on Construction History, pp. 1887-1988, Instituto Juan de Herrera, Madrid.

Taín Guzmán, M. 2006: "Fifteen Unedited Engraved Architectural Drawings Uncovered in Northwest Spain", en Dunkeld, M. ed., Proceedings of the Second International Congress on Construction History, pp. 3011-3023, Construction History Society, Cambridge.

Taín Guzmán, M. 2009: "La utilización de monteas en la construcción en piedra: El caso gallego", en El arte de la piedra, pp. 71-202. Madrid, CEU Ediciones.

Taín Guzmán, M. y Natividad Vivó, P. 2011: "La montea para las bóvedas de horno de Santa Columba de Carnota”, en S. Huerta, I. Gil, S. García, M. Taín (eds.), Actas del Séptimo Congreso Nacional de Historia de la Construcción, pp. 1387-1399. Instituto Juan de Herrera, Madrid.

Taín Guzmán, M., Alonso Rodríguez, M. Á., Calvo López, J. y Natividad Vivó, P. 2012: "Stonecutters' literature and construction practice in Early Modern Gothic. The tracings for a rib vault at the Cathedral of Tui", Construction History, $\mathrm{n}^{\mathrm{o}} 27$, pp. 1-21.

Taton, R. 1950: Gaspard Monge. Birkhäuser, Basel.

Taton, R. 1954: L'Histoire de la géométrie descriptive. Université de Paris, Paris.

Thoenes, C. 1993: "Vitruv, Alberti, Sangallo. Zur Theorie der Architekturzeichnung in der Renaissance". In Beyer, Andreas, ed., Hülle und Fülle: Festschrift für Tilmann Buddensieg, pp. 565-584. VDG, Weimar.

Tornés, familia c. 1700: Libro de trazas de la arquitectura jacetana. Huesca, Archivo Histórico Provincial de Huesca. 
Tosca, T. V. 1707-1715: Compendio mathemático, en que se contienen todas las materias más principales de las Ciencias, que tratan de la cantidad.... Antonio Bordazar - Vicente Cabrera, Valencia.

Vandelvira, A. d. 1977: Tratado de arquitectura de Alonso de Vandelvira. Barbé-Coquelin de Lisle, ed. Caja Provincial de Ahorros, Albacete.
Vigo Trasancos, A. (dir.) 2011: Catálogo de planos y dibujos. Galicia y el siglo XVIII. Planos y dibujos de arquitectura y urbanismo (1701-1800). Fundación Pedro Barrié de la Maza, A Coruña.

Willis, R. 1842: "On the construction of the vaults of the Middle Ages". Transactions of the Institute of British Architects, vol. 1, pp. 1-69. 